\title{
CONFABULATIONS IN SCHIZOPHRENIA
}

\author{
A dissertation submitted \\ to Kent State University in partial \\ fulfillment of the requirements for the \\ degree of Doctor of Philosophy
}

by

Mohammed Shakeel Kalathil

December, 2014

(C) Copyright

All rights reserved

Except for previously published materials 
Dissertation written by

\author{
Mohammed Shakeel Kalathil \\ B.A., Bangalore University (India), 2003 \\ M.A., University of Kerala (India), 2005 \\ Ph.D., Kent State University, 2014
}

Approved by

Nancy M. Docherty, Professor, Ph.D., Department of Psychological Sciences, Doctoral Advisor

Maria S. Zaragoza, Professor, Ph.D., Department of Psychological Sciences

John Gunstad, Professor, Ph.D., Department of Psychological Sciences

Christopher Was, Professor, Ph.D., Department of Education

Sara Newman, Professor, Ph.D., Department of English

Accepted by

Maria S. Zaragoza, Professor, Ph.D., Chair, Department of Psychological Sciences

James L. Blank, Dean, Ph.D., College of Arts and Sciences 


\section{TABLE OF CONTENTS}

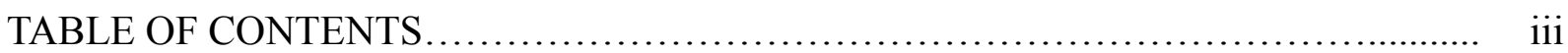

LIST OF TABLES $\ldots \ldots \ldots \ldots \ldots \ldots \ldots \ldots \ldots \ldots \ldots \ldots \ldots \ldots \ldots \ldots \ldots \ldots \ldots \ldots \ldots \ldots \ldots \ldots . . \quad \mathrm{V}$

ACKNOWLEDGEMENTS .......................................................... vi

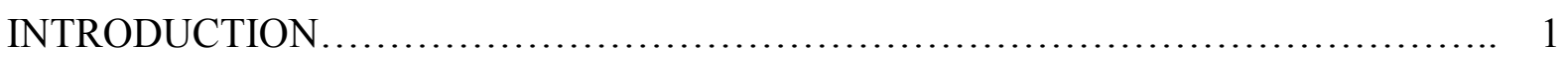

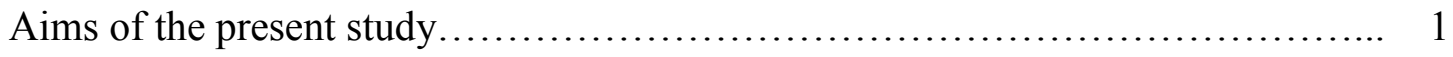

Definition............................................................... 3

Types of Confabulation.............................................. 4

Theories of Confabulation........................................... 7

Schizophrenic Confabulations............................................ 17

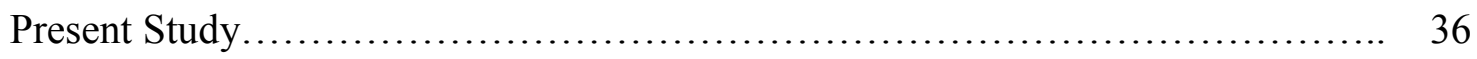

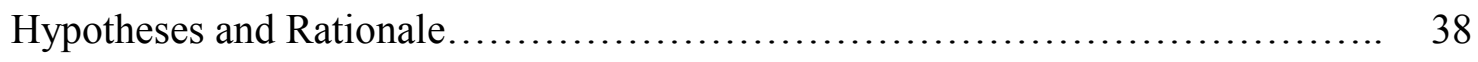

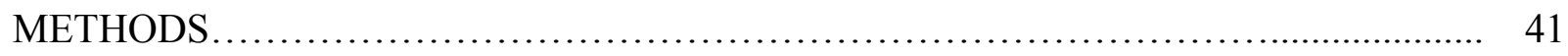

Participants..................................................... 41

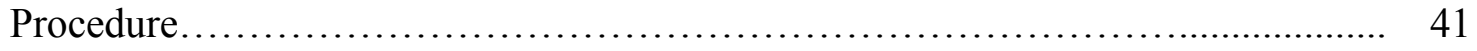

Measures................................................................. 42

Data Analysis Plan................................................ 50

RESULTS.................................................................. 54

Socio-Demographic Details............................................. 54

Tests of Hypotheses................................................ 54

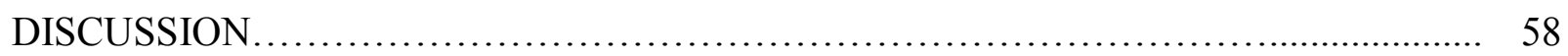

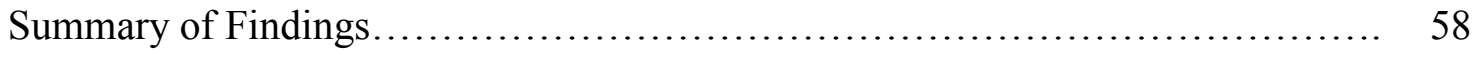


Interpretation of Findings.................................................. 59

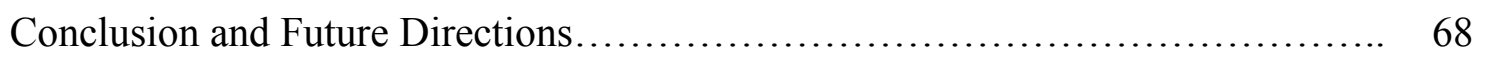

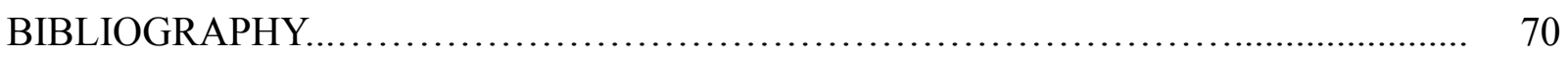

APPENDIX A. CONFABULATION CODING SCHEME ............................... 98 


\section{LIST OF TABLES}

Table 1. Socio-Demographic Details........................................... 87

Table 2. True and false memories, Mean (Standard Deviation) ......................... 89

Table 3. Means and standard deviations for elements, cognitive, language related and psychopathology variables in schizophrenia patients........................... 90

Table 4. Correlations between Temporal Confusions, True Memory, Executive

Functions, Source Monitoring, and Confabulation Elements $(n=56) \ldots \ldots \ldots \ldots \ldots \ldots \ldots \ldots . . \ldots 1$

Table 5. Regression of True Memory, Executive Functions, and Source Monitoring

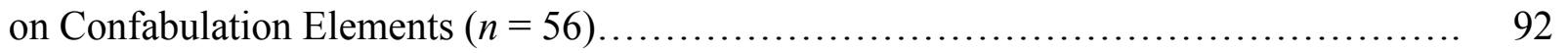

Table 6. Correlations of Language, Formal Thought Disorder, and Verbal Fluency

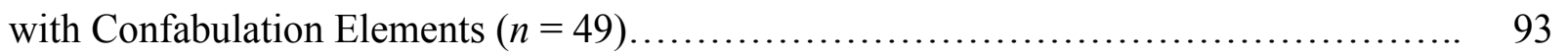

Table 7. Regression of Language, Formal Thought Disorder, and Verbal Fluency

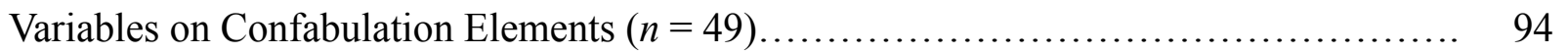

Table 8. Correlation of Confabulation Elements with Hallucinations and Delusions

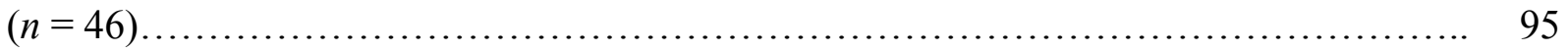

Table 9. Regression of Positive Symptoms on Confabulation Elements $(n=46)$. 


\section{ACKNOWLEDGEMENTS}

Illness is neither an indulgence for which people have to pay, nor an offense for which they should be penalized, but a misfortune, the cost of which should be shared by the community. --Aneurin Bevan

I would like to thank Dr. Nancy Docherty, Dr. Maria Zaragoza, Dr. John Gunstad, Dr. Christopher Was, Pat Rich, Gabriela Mance, and my colleagues at the Schizophrenia Research Lab.

I would also like to thank mom, dad, and my wife. I rarely get the opportunity to thank them in my works but without their love and endless patience none of this would have been possible. Most of all I would like to thank our patients. It is an unfair relation where we have learned so much from them and have had so little to offer in return, yet they come every day to participate in our studies. Having the unique misfortune of suffering from a devastating illness that also only affects a small part of the population, schizophrenia patients are affected the most at a time when what little was being spent on health care and research is increasingly being directed away to unworthy causes. As scientists we may hope (though it seems increasingly unlikely) that we will find effective treatments for the condition, but there is no doubt that as a society we have failed them. 


\section{Introduction}

He not only recalls facts, but also things said in his presence, possibly even his dreams, and all of this is now part of his consciousness...If he remembers something, he cannot decide whether it happened in reality or whether he dreamed it: the trace left by a real incident is only little different from the one left by... an idea. (Korsakoff, 1889, p. 514)

Confabulations are a relatively rare form of false memories found in severe neuropsychiatric conditions like Korsakoff's psychosis, anterior communicating artery aneurysm (ACoA), Alzheimer's disease, some types of traumatic brain injury (TBI), bipolar disorder, and schizophrenia. Confabulations are intriguing phenomena which have the potential to tell us more than we currently know about the mechanisms of memory, and how their breakdown can result in memory errors. Most of what we know about confabulation comes from studies of neurological conditions and it has not been examined whether the theories derived from these conditions can also account for confabulations in psychiatric conditions like schizophrenia.

\section{Aims of the present study}

There have been several classifications of confabulation and various theories have been proposed. The purpose of the current investigation is to evaluate these theories and examine them based on evidence from schizophrenia. Understanding confabulations from the perspective of schizophrenia is important for at least 2 reasons:

1. Schizophrenia has a pathophysiology that differs from other conditions in which 
2. confabulations are observed (ACoA, Alzheimer's dementia, Korsakoff psychosis, TBI, etc.) and any theory that claims to account for confabulation should be able to account for its occurrence wherever it is found, and not just in organic psychosis.

3. Schizophrenia provides a unique opportunity for evaluating competing theories because the candidate deficits implicated by various theories - temporal context confusions, executive functioning, memory and monitoring deficits - are all present in schizophrenia, often simultaneously (Lorente-Rovira, Pomarol-Clotet, McCarthy, Berrios, \& McKenna, 2007; Nathaniel-James \& Frith, 1996; Nathaniel-James, Foong, \& Frith, 1996).

The few studies which have investigated schizophrenic confabulation (Lorente-Rovira et al., 2007; Lorente-Rovira, Santos-Gomez, Moro, Villagrán, \& McKenna, 2010; Nathaniel-James \& Frith, 1996; Nathaniel-James et al., 1996) suggest that schizophrenic confabulations may differ from other neuropsychiatric conditions in their characteristic features and underlying cognitive and neural mechanisms (Gilboa, 2010). However, these studies are limited by the use of relatively simple paradigms to study the phenomena and a failure to collect sufficient data about relevant cognitive and metacognitive functions. The aims of the current investigation are:

1. To investigate and describe the features of confabulation in schizophrenia.

2. To evaluate existing theories of confabulation using data from schizophrenia.

3. To determine the relation of schizophrenic confabulation with cognitive and metacognitive functions implicated by current theories-e.g., memory, executive functions, temporal context confusion, and source monitoring.

4. To investigate the relation of schizophrenic confabulations with the positive symptoms of schizophrenia, esp. delusions and formal thought disorder. 


\section{Definition}

Earliest descriptions of confabulation can be found in the works of Korsakoff (1889).

Shortly afterwards, the term confabulation appears in the works of Kraepelin (1971) (who called it paraphrenia confabulans), Wernicke (1906), and Bonhoeffer (1904). Confabulations can occur in a wide range of neuropsychiatric conditions like Dementia of Alzheimer's type, Korsakoff's syndrome, ACOA, TBI, bipolar disorder, and schizophrenia. It can also occur, often in simpler forms, among healthy people (La Corte, George, Pradat-Diehl, \& Barba, 2011; Salazar-Fraile et al., 2004; Zaragoza, Payment, Ackil, Drivdahl, \& Beck, 2001; see review Lorente-Rovira, Berrios, McKenna, Moro Ipola, \& Villagrán Moreno, 2011; Lorente-Rovira, McKenna, Berrios, Villagrán Moreno, \& Moro Ipola, 2011). The descriptions of confabulation have often reflected the specific population and type of confabulation to which the theorist was exposed.

- Berlyne (1972) defines it as a "Falsification of memory occurring in clear consciousness in association with an organically derived amnesia”.

- Kopelman, Guinan, \& Lewis (1995) define it as "Erroneous memories, either false in themselves or resulting from true memories misplaced in context and inappropriately retrieved or interpreted".

- Gilboa et al. (2006) define it as "Statements or actions that reflect unintentional but obvious distortions of memory".

- Moscovitch (1989) defines it as "honest lying".

There have been several other descriptions of confabulation (Burgess \& McNeil, 1999; Christodoulou, 1977; Kopelman et al., 1995; Moscovitch \& Melo, 1997), and each of them emphasizes a different facet of the etiology, features, or mechanisms of confabulation. Two features, however, stand out across all these descriptions. 
1. Confabulations are false memories - either false in content, or false in the given context.

2. The confabulator is not aware of the falsehood of these claims. They often hold on to it as a healthy person would to a genuine memory.

The confabulator not only produces false information unintentionally, but is also genuinely not aware that it is false.

\section{Types of Confabulation}

Although any falsification of memory can be considered a confabulation, they often differ significantly from each other. The term confabulation can be used to describe false alarms on a memory test, intrusion errors, false elaborations on a true memory, denial of illness (anosognosia) or denial of blindness (Anton's syndrome). It can also be used to describe claims such as that one is a pirate on a spaceship, or witnessed a murder, or that the patient's spouse has been replaced by an imposter (Capgras delusion) (Christodoulou, 1977; Damasio, Graff-Radford, Eslinger, Damasio, \& Kassell, 1985; Stuss, Alexander, Lieberman, \& Levine, 1978).

Confabulations may differ substantially from each other, and while paraphrasing or intrusion errors can be found even in the healthy population, only patients with (often severe) neuropsychiatric conditions report illogical or bizarre ideas. It has therefore been theorized that there may be different types of confabulation, with different underlying mechanisms (Kopelman, 2010).

\section{Early classifications-Bonhoeffer and Kraepelin}

Bonhoeffer (1901) proposed one of the earliest classifications of confabulation when he distinguished confabulations of embarrassment from fantastic confabulations. While he attributed the former to memory loss and a need to cover-up this deficit, he believed fantastic 
confabulations went beyond this state of emergency and resembled delirium or delusions of grandeur. Similarly, Kraepelin (1971) defined simple confabulations as minor factual errors while reserving the term fantastic confabulations for more florid and bizarre ideas.

\section{Kopelman's Provoked and Spontaneous confabulation}

More recently, Kopelman $(1987 ; 2010)$ proposed dividing confabulation into two typesProvoked and Spontaneous.

- Provoked confabulations occur in response to questioning, tend to be brief, and serve a "gap filling" function in the presence of defective memory. It is a normal response to defective memory and can be found even in healthy people.

- Spontaneous confabulations tend to be elaborate (or bizarre), may occur naturally, and do not serve (or go beyond) a gap-filling function. They result from a combination of amnesia and frontal dysfunction, and are exclusively found in people with specific neurological conditions.

Kopelman's classification has been criticized because it is often difficult to distinguish provoked from spontaneous confabulations (Gilboa et al., 2006). However, it remains a useful and widely used classification because his contention that even healthy people can confabulate in

response to task demands (Zaragoza et al., 2001), but only patients with specific neuropsychiatric conditions tend to spontaneously generate false memories has been supported by empirical evidence (Burgess \& McNeil, 1999; Christodoulou, 1977; Nathaniel-James \& Frith, 1996; Nathaniel-James et al., 1996).

\section{Schnider's classification}

The most elaborate classification of confabulation so far was proposed by Armin Schnider (2008). His classification includes four categories: 
- Intrusions involve distortions when a person is pushed to recall details from memory.

- Momentary confabulations can occur in response to questioning (provoked) or spontaneously. They are characterized by being "conceivable and inherently plausible, although they may be incompatible with (the person's) current...circumstances" (p.63)

- Fantastic confabulations have no basis in reality and are logically inconceivable.

- Behaviorally spontaneous confabulations are characterized by the patient's tendency to act on their confabulations. e.g., a patient who dresses up every morning believing he has to get to work (Burgess \& McNeil, 1999).

Schnider's classification (2008), like Kopelman's, suffers from the problem of distinguishing various types of confabulations in clinical settings. Though confabulations observed in patients may not always neatly fall into categories, his classification rightly places its emphasis on both content and severity in distinguishing various types of confabulation. A patient with Capgras delusion who calls the police on her husband (Christodoulou, 1977) arguably suffers from a more serious form of confabulation than someone who does not act on their false ideas. This is analogous to the clinical practice of rating symptoms (e.g., hallucination, delusion) as more severe when the patient acts on them.

Each of the different classificatory systems has its own advantages and disadvantages, but given that classifying confabulations into more types makes it difficult to distinguish them in research/clinical settings, it needs to be determined what are the minimum number of divisions that can account for most of the data. There may be some inherent value to classifying confabulations as provoked or spontaneous as they potentially represent two different mechanisms of confabulation formation. 


\section{Theories of Confabulation}

\section{Gap-filling account}

The oldest, and seemingly intuitive, theory of confabulation suggests that patients confabulate in an effort to fill gaps in their memory. Kraepelin (1971) was an early proponent of this view and even present day references and textbooks (American Psychiatric Association, 1994; Semple \& Smyth, 2005) often attribute confabulations to the patients' need to avoid embarrassment, despite the fact that there is little empirical evidence to support this view (Mercer, Wapner, Gardner, \& Benson, 1977).

Schnider and colleagues (Schnider, von Däniken, \& Gutbrod, 1996) provided confabulating and non-confabulating amnesics with questions that either covered real items ('who is Prince Charles?') or non-existent items ('what is a vibrasse?') to determine whether (provoked/spontaneous) confabulating patients have an increased tendency to answer the nonexistent questions. They found that confabulating and non-confabulating amnesics did not significantly differ on the number of answered fake questions, suggesting that confabulators do not indiscriminately try to fill gaps in their memory. More importantly, confabulators do not know about their memory deficit, so it is difficult to argue that they are trying to deliberately fill in gaps in their memory to avoid embarrassment (see Lorente-Rovira et al., 2011a; 2011b).

\section{Temporality Theory}

The basic idea underlying temporality theories is that confabulations occur because true memories are misplaced in time, and become irrelevant in the given context. They may correctly remember the content, but fail to recognize the chronological order of events (see Korsakoff, 1889; Lorente-Rovira et al, 2011a; 2011b). There are two versions of this account—one by Dalla Barba and the other by Armin Schnider and colleagues. 
Dalla Barba and colleagues attribute confabulation to a disturbance in personal temporality. According to them (Dalla Barba, 1993a; Dalla Barba, 1993b; Dalla Barba \& Decaix, 2009; Gilboa, 2010) temporality--or the sense of one's existence with reference to the past, present, and future--is central to consciousness. There can be two kinds of consciousness. Knowing consciousness relates to categorical entities like habits and semantics (which do not have/do not require, time tags), while temporal consciousness relates to specific entities like autobiographical events which are specified in time. According to this theory, when there is a disruption in temporal consciousness, patients fall back to relying on the more stable information from knowing consciousness. This results in patients confusing habitual, generic and welllearned information for specific events, which they term habits confabulation (Gilboa \& Verfaellie, 2010; La Corte et al., 2011). Also, the three types of temporality-for past, present, and future - map onto three types of confabulations- for past episodic memories, temporalspatial disorientation, and future plans, respectively.

In a case-study, La Corte et al. (2011) showed that a patient with ruptured right internal carotid siphon aneurysm confabulated (only) on questions related to temporal consciousness, like autobiographical information ("What did you do yesterday?", "I was at the Montpellier University to give a lecture"), orientation to time and place ("Where are we now?", "We are in the French Oil Department"), and personal future ("What are you going to do tonight?", "I will go back home and will have dinner with my wife") (p.311). For every question, the patient recalled a memory from his past which was generally true, though not true with respect to the time period specified in the question. However, the patient did not confabulate about questions which referred to knowing consciousness—-semantic memory, impersonal future, etc. 
Dalla Barba's theory can account for many of the confabulations encountered in patient populations, and there are studies which have shown that highly engraved habits and routines do play a role in the production of confabulations (Nahum, Ptak, Leemann, Lalive, \& Schnider, 2010). Schnider (2008) found that patients with behaviorally spontaneous confabulations often have a disturbed sense of time, independent of memory deficits. However, the theory falls short of explaining the more bizarre kinds of confabulations which do not draw from one's personal past (Moscovitch, 1995); therefore the theory can only account for a subset of confabulations. Dalla Barba's account has also been criticized for lacking adequate empirical support for some of its claims (see Schnider, 2008).

The other version of temporality theory, best described by Schnider and colleagues (Schnider, 2008; Schnider, Ptak, von Däniken, \& Remonda, 2000), states that confabulators are unable to suppress previously activated, but currently irrelevant memory traces, which results in past memories intruding into the present (they call this temporal context confusion). Schnider and colleagues (Nahum, Ptak, Leemann, \& Schnider, 2009; Schnider, 2008; Schnider, Guggisberg, Nahum, Gabriel, \& Morand, 2010) implicate a failure of the (dopamine mediated) reward system of the brain in the failure to suppress currently irrelevant information (esp. in the case of behaviorally spontaneous confabulation; see Gilboa \& Verfaellie, 2010). Schnider's account is similar to Dalla Barba's in its emphasis on the irrelevance of retrieved memories with respect to the current context, but it differs from Dalla Barba in its emphasis on proactive interference as the primary source of confabulations.

Schnider et al. (Schnider \& Ptak, 1999; Schnider, 2003) presented spontaneous confabulators with a set of pictures where the task was to identify which of the pictures recurred. In a second run, they were presented with the same set of pictures arranged in a different order. 
They were asked to forget what they had seen during the first presentation and indicate which of the pictures recur in the second presentation. They found that confabulators (unlike nonconfabulating amnesics and healthy participants) were unable to suppress the memory of what they had seen in the first set, resulting in high rates of false-positive responses (or temporal context confusion). In subsequent studies, they also showed that recovery from spontaneous confabulation was associated with recovery from temporal confusions in memory (Schnider, Ptak, von Däniken, \& Remonda, 2000), that temporal context confusion distinguishes confabulating from non-confabulating amnesics (Nahum et al., 2009), and that performance on tasks that measure temporal context confusion (like the continuous recognition task) activates the posterior orbitofrontal cortex of healthy participants, which is one of the areas commonly lesioned in confabulating patients (Schnider, 2003).

Not all studies find temporal context confusion to be unique to confabulators and it has been found in non-confabulating amnesic patients as well (Gilboa et al., 2006; Metcalf, Langdon, $\&$ Coltheart, 2007). Other studies have failed to show that all confabulators perform as expected on Schnider's task (Bajo \& Kopelman, 2008; Kopelman, 2010). More importantly, not all confabulations involve confusing the past for the present. A Capgras delusion patient who claims her husband had been replaced by an imposter (Christodoulou, 1977), an ACoA patient who claims to have met a woman with a bee's head (Turner, Cipolotti, \& Shallice, 2010) or a schizophrenia patient who claims to have committed murder (McKenna, 2007) cannot be said to be confusing their past memories with the present.

Both Dalla Barba and Schnider's temporal accounts fail to fully account for complex/bizarre false memories in terms of a reliance on the stable elements of autobiographical memories (knowing consciousness) or temporal displacement of true memories. 


\section{Source monitoring and Temporality theory}

A significant limitation of the temporality account is that their findings can be better (and more parsimoniously) accounted for by the source monitoring theory. The fundamental idea of source monitoring is that memories do not come with tags specifying their origins for us; rather, we have to attribute them to specific sources using heuristic and systematic decision processes, based on evaluation of cues such as contextual and sensory/perceptual information, cognitive operations and semantic detail (Johnson, Hashtroudi, \& Lindsay, 1993; Johnson \& Raye, 2000; Lindsay, 2008). Such discriminations may involve external sources ("Did Mary say that, or did Jane?"), internal sources (“Did I just think about it, or did I actually say it?"), or internal vs external sources — reality monitoring (“Did I imagine it, or did I hear it?") (Johnson \& Raye, 1981). Cognitive functions can affect the evaluative processes involved in making these judgments, and disruption in the more extended reasoning processes can result in confabulation (Hashtroudi, Johnson, Vnek, \& Ferguson, 1994; Johnson et al., 1993; Lindsay, 2008; Shakeel \& Docherty, 2012).

From a source monitoring perspective, Dalla Barba's habits confabulation can be accounted for in terms of a failure to determine the source of various retrieved information. Similarly, Schnider's (2003) finding that confabulators fail to suppress answers from a previously presented sequence can be accounted for in terms of a source monitoring failure to discriminate between items in the two presentations. The advantage of the source monitoring theory (Johnson et al., 1993) is that it is a broad framework that includes many different kinds of discrimination, time being just one of them, so it can account for more than just the data from temporal theories. For instance, when a patient claims to have died because of a gunshot wound (Stuss et al., 1978, it is hard to argue they are confusing their personal past (or future) with the present, but source- 
monitoring can account for this in terms of a (reality monitoring) failure to distinguish between imagination and perception.

In a study with three confabulating ruptured ACoA patients, Turner and colleagues (2010) tried to replicate Schnider and Ptak (1999) findings using a repeated continuous recognition task. They also measured source monitoring ability to assess the possible underlying mechanism which, according to Schnider's theory, filters old memory traces that intrude into the present. They found that confabulating patients were severely impaired on temporal source-monitoring and could not identify the source of familiarity for items they recognized. However, they did not show a specific tendency for previous memory traces to intrude forward into the present. More importantly, this impairment was not limited to temporal information. Unlike healthy participants, these patients showed a significant bias toward misidentifying words they had only imagined as having come from an external source (heard) on a reality-monitoring task. These findings suggest that temporality deficits in these patients may represent one aspect of a more generalized (source-monitoring) deficit in the ability to distinguish among different contexts/sources of information (Gilboa \& Verfaellie, 2010).

Temporality theorists (Dalla Barba, 1993a; Dalla Barba, 1993b) have criticized sourcemonitoring theory stating that it cannot account for confabulations that are only observed for episodic (but not semantic) memories. From a source-monitoring perspective, episodic memories may be more error-prone due to greater task demands placed by episodic retrieval (e.g., semantic memory does not require retrieval of time information) (Metcalf et al., 2007). In other words, there are more ways to get an episodic memory wrong.

Despite being theoretically plausible, there is lack of adequate empirical evidence supporting a specific association of source monitoring deficits with confabulation. Studies by 
Ciaramelli and Ghetti (2007) and Johnson (Johnson, O'Connor, \& Cantor, 1997) failed to find an association between source-monitoring deficits and confabulation. Studies have also documented source-monitoring errors in non-confabulating patients (Metcalf et al., 2007; Kopelman, Ng, \& Brouke, 1997; Johnson et al., 1997). Even the neural substrates of source-monitoring [dorsolateral prefrontal cortex (DLPFC) and Broadmann area 10/46 (Johnson \& Raye, 1998)] differ from those of confabulation [orbitofrontal and ventromedial prefrontal cortex (PFC)]

(Gilboa \& Moscovitch, 2002). In summary, source monitoring deficits are neither necessary nor sufficient for confabulations to occur. However, given the evidence of their association with confabulation (Gilboa \& Verfaellie, 2010; Turner et al., 2010) source-monitoring deficits may be more accurately viewed as a feature rather than a cause of confabulation, and as one of several factors that contribute to it (Johnson, Hayes, D'Esposito, \& Raye, 2000; Schnider, 2008).

\section{Retrieval account}

Retrieval theories view confabulation primarily as the result of failure in retrieval/reconstructive processes (Schacter, Norman, \& Koutstaal, 2000). The hippocampal complex plays a central role in this model and enables formation of complex memories by joint activation of inputs from multiple sources, though these memories are not stored in any specific temporal or subject order (Gilboa \& Moscovitch, 2002; Moscovitch \& Winocur, 2002).

According to this model, there are two pathways to memory activation - associative/direct and strategic/indirect retrieval (Moscovitch \& Winocur, 2002). In the direct route, a cue automatically activates the memory (mediated by the medial temporal lobes (hippocampus) and related structures). However, when the cue is ineffective an indirect route is used for a more deliberate and effortful search process. Firstly, a retrieval mode is established (DLPFC) which formulates the problem and defines the goals of the task. Then the cues needed to gain access to 
the memory (in hippocampus) are specified (by ventrolateral PFC) to guide the search. Once the memory is retrieved, it is evaluated (by ventromedial PFC and frontal pole) to determine whether it meets the search goals (set by DLPFC), before being accepted. In case of uncertainty, the strategic verification process which involves diverse regions of the frontal (DLPFC) and posterior neocortex is engaged. These regions provide information about the recovered memory, such as its compatibility with previous knowledge, perceptual characteristics, etc. (Gilboa \& Moscovitch, 2002). Finally, the memory is placed in its proper spatial-temporal context (Conway \& Tacchi, 1996; Moscovitch, 1995; Moscovitch \& Melo, 1997).

In this model, most confabulating patients have a specific strategic retrieval difficulty rather than an associative retrieval difficulty. Confabulations can result from a defective search component (resulting in failed search strategies and retrieval) interacting with monitoring deficits (resulting in an inability to reject/suppress inaccurate information (mediated by the mid-DLPFC and ventromedial PFC) (Gilboa \& Moscovitch, 2002; Moscovitch \& Melo, 1997). Of these, errors in the output processes involved in monitoring, evaluation and verification of recovered memory traces seem to be more important (Moscovitch, 1995). If a retrieval cue is inadequate, it may result in omissions. But if a cue lacks specificity, confabulations can occur (Metcalf et al., 2007). In summary, the retrieval model states that confabulations result from an interaction of faulty memory system, faulty search processes, and a defective monitoring process which is unable to edit out the faulty memories (Gilboa \& Moscovitch, 2002).

There are other theories which may be broadly considered retrieval accounts. Turner and Coltheart (2010) propose a two factor monitoring account which suggests that unconscious processes identify and tag the content which has to be checked by conscious evaluative processes. A failure of this monitoring process results in ideas, which were to be checked and 
rejected, to be uncritically accepted instead. They claim that including conscious and unconscious monitoring processes results in a model that can account for delusions as well as confabulations.

Unlike Temporality accounts, retrieval theory emphasizes the role of errors in retrieval processes in the formation of false memories. This is partially supported by the observation that confabulations affect remote memories as well as memories acquired after the onset of illness or trauma (Fotopoulou, 2010) because encoding deficits cannot affect memories which were formed before the onset of injury/illness.

Moscovitch and Melo (1997) compared confabulating amnesics with non-confabulating amnesics and healthy controls by asking them to describe personal experiences and historical events in response to specific cue words. Firstly, confabulating amnesics produced fewer memories than the other groups, which suggests poor search strategies. Secondly, confabulating amnesics produced significantly more false details than non-confabulating amnesics. Finally, compared to non-confabulating amnesics and healthy controls, confabulating patients produced significantly more secondary confabulations when prompted to generate details, which indicates a failure of the monitoring processes in confabulation. They note that memory errors may occur if search mechanisms are faulty, but confabulations only occur when monitoring of the retrieved information is impaired.

Retrieval accounts have made predictions which have been largely supported by empirical investigations. Remarkably, the model itself has evolved over time to acknowledge the importance of other factors like source-monitoring, perseveration, temporal context confusions, and motivational factors (Gilboa, 2010). 
On the other hand, although encoding deficits may not play a role in confabulation for events that occur before the onset of illness/injury (Fotopoulou, 2010), they may play a role in confabulation for memories which occur after the onset of the illness/injury. Retrieval theories fail to acknowledge this.

The strategic retrieval account suggests confabulations do not have a temporal gradient, i.e., that they occur equally for remote as well as recent memories (because it is only the search/retrieval process that is disrupted and not the memory itself) (Metcalf et al., 2007). Although some patients do not show a temporal gradient in confabulation (Conway \& Tacchi, 1996), others do (Box, Laing, \& Kopelman, 1999; Dalla Barba, Mantovan, Cappelletti, \& Denes, 1998; Schnider et al., 1996), indicating that not all patients confabulate equally across all time periods. For instance, Dalla Barba et al. (1998) describes the case of a patient with amnesic confabulatory syndrome (following heart arrest) who showed severe confabulation for recognition of photographs in the eighties which decreased consistently for recognition of photos representing people and events from earlier decades (the accuracy of true memory followed the opposite pattern with recognition of older photographs being more accurate compared to recent ones).

Retrieval theories suggest that confabulations can occur for semantic as well as episodic memories (see Moscovitch \& Melo, 1997) but there have been studies which have shown confabulators who produced few, if any, semantic confabulations (Barba, 1993; Dalla Barba, Cipolotti, \& Denes, 1990). Gilboa and Moscovitch (2002) respond to this by suggesting that confabulations are more common in episodic memories because the process of strategic retrieval is more central to recovering the more complex episodic memories than semantic memories (which don't require determining time and place) (Moscovitch, 1989; Moscovitch, 1995). 
The emphasis on executive functions may be misplaced. Studies have shown patients can confabulate despite having intact executive functions (Dalla Barba, 1993a; Dalla Barba, 1993b; Nedjam, Barba, \& Pillon, 2000).

Some have criticized the emphasis placed on hippocampal complex for reactivation of memory (ecphory) (Squire \& Bayley, 2007). Others have pointed out there is little evidence to support the idea that the ventromedial prefrontal cortex and frontal pole are involved in determining the accuracy of retrieved memories (see Schnider, 2008).

The strategic retrieval theory suggests confabulations are caused by specifiable lesions, but it fails to account for why these lesions so infrequently cause permanent confabulation or even, at times, any confabulation at all (see Alexander, 2011).

Though most of the current evidence supports the retrieval model, no single account of confabulation at present receives unequivocal support. This may be, in part, owing to the fact that different neuropsychiatric conditions (e.g., Alzheimer's dementia, TBI, Korsakoff psychosis) present with different cognitive profiles, and it is rare to consistently find all the cognitive/metacognitive deficits the different theories implicate in any single condition. The other as yet unresolved issue pertains to the relative contribution of the different theories with respect to different types of confabulations. For instance, the gap filling account fails to account for spontaneous confabulations, but can it contribute to provoked confabulations? Similarly, what is the relative contribution of temporal context confusions or source-monitoring deficits to confabulation? The answers to these questions require investigating the phenomenon in conditions characterized by extensive cognitive deficits, like schizophrenia.

\section{Schizophrenic Confabulations}

\section{Features}


Most recent descriptions (e.g., Berlyne, 1972) of confabulations focus on their occurrence in neurological patients, but even as early as 1919 Kraepelin described paraphrenia confabulans in patients with schizophrenia who "bring forward with the most profound conviction an enormous number of extraordinary stories absolutely in the form of personal experiences" (Kraepelin, 1971, p. 311). For instance, one patient Kraepelin describes reported to the authorities that he had dug up a human arm and was later compelled at gunpoint to remain silent about it. Current evidence suggests that schizophrenia not only presents with a new pathology which allows us to evaluate competing theories of confabulations, with different underlying cognitive and neural mechanisms (see Gilboa, 2010) but also presents with a fundamentally different kind of confabulation.

Nathaniel-James and Frith (1996) asked schizophrenia patients and healthy controls to recall Aesop fables which were read out to them. One of the fables was the following:

A rich man took a valuable cargo on a voyage across dangerous seas. A storm soon blew up and the ship went down throwing the passengers into the sea. They all began to swim for their lives except the rich man who raised his arms to heaven and promised his God all kinds of riches if he was saved. The other passengers shouted to the praying man, 'Don't leave it to God to save you, swim for yourself'.

They found that every schizophrenia patient (but only one control participant) added some information not present in the story during retrieval. For instance, one patient's recollection was:

A rich man went on a swimming expedition and he stopped swimming in the middle of the ocean. In the middle of the ocean he decided that he would pray to our Lord God...he would pray to God, our Lord...Jesus who would...um...Jesus our Lord, who would accept 
his prayer...answered prayer. But he carried on praying as was his word and he was hailed by people on a passing boat who said, 'God won't help you, swim for yourself'. Although schizophrenia patients do invent entirely new information (e.g., McKenna, 2007), studies have shown they differ from neurological patients (e.g., Kopelman, 1987) in also having a tendency to reorganize and restructure the original story (Kopelman, 1999; NathanielJames \& Frith, 1996; Nathaniel-James et al., 1996; Lorente-Rovira et al., 2007). In the above fable, the idea of a swimming expedition and passing boat in the patient's recall probably comes from the reference to passengers swimming and mention of the boat in the original story (Nathaniel-James \& Frith, 1996). Nathaniel-James and Frith (1996) point out that this pattern of confabulation differs from that of neurological patients, where entirely new material is introduced during confabulation (e.g., Kopelman, 1987). A later study by a different group (Lorente-Rovira et al., 2007) replicated these findings and found both re-organized and new material in the confabulations produced by schizophrenia patients. However, the new information generated by the schizophrenia patients differed from the gross inventions described in patients with amnesia and dementia (e.g., Kopelman, 1987) in that they were generally constrained by the context of the story. For example (from Lorente-Rovira et al., 2007), a patient recalled, 'A laborer was trying to chop a tree down with his axe. He broke the axe' [Original story: 'A laborer worked along a stream. His axe fell (into the water)...']. In a neurological study, on the other hand, one amnesia patient recalled the Wechsler memory story (Anna Thompson) about a woman being robbed by stating that the woman worked in a pub to make the money and that her husband had left her, neither of which are stated in, or can be reconstructed from elements in the original story (Kopelman, 1987; McKenna, Lorente-Rovira, \& Berrios, 2009). While this pattern of findings partially supports the temporality theory, temporality theory 
cannot account for the fact that the patients do not just displace the sequence of events but also tend to restructure/reorganize it to mean something new. Furthermore, as with neurological conditions (see Christodoulou, 1977; Moscovitch, 1995; Schnider, 2008; Turner et al., 2010), temporality theory cannot account for the more bizarre kinds of confabulation which do not draw from one's personal past, or involve confusing the past for the present (e.g., McKenna, 2007).

Interestingly, these findings cannot be accounted for fully by the strategic retrieval account either, because the patients are not randomly retrieving erroneous information and failing to reject it. They are, instead, reorganizing and reconstructing elements in the original story. Retrieval accounts primarily implicate retrieval deficits in the formation of confabulations, but evidence from schizophrenia suggests the involvement of encoding as well as retrieval deficits in schizophrenia. For instance, when Nathaniel-James and colleagues (1996) presented schizophrenia patients with their own confabulated recall, they often claimed their recollections were accurate (the patients thought their implausible stories were overall "all right"). This suggests the patients are not able to correct their stories because they are represented abnormally at the encoding phase and are disorganized even before they are retrieved. This deficit is further compounded by a faulty editing process at output (Morais, Frith, \& Dab, 2004). Nathaniel-James and colleagues (1996) suggest that this differs from retrieval theories which implicate strategic retrieval processes based primarily on observations of neurological patients with impaired free recall but preserved recognition (see Moscovitch, 1989). Kramer (Kramer, Bryan \& Frith, 1998) presented schizophrenia patients with a sequence of pictures they had to combine into a story in a narrative discourse task. Despite the fact that the pictures remained in front of the participants throughout the task, the patients produced stories which were very different from those of healthy participants. The authors attributed this to patients interpreting the stories differently 
(Kramer et al., 1998). Schizophrenia patients' tendency to confabulate even in the absence of a memory component further supports the role of faulty encoding processes in the formation of confabulations.

The evidence, therefore, suggests that prospective monitoring is not sufficient to avoid confabulations in schizophrenia (Lorente-Rovira et al., 2010; Morais et al., 2004). Monitoring may be crucial for neurological confabulations (see Gilboa et al., 2006), but schizophrenic confabulations also implicate encoding processes (Kramer et al., 1998; Lorente-Rovira et al., 2010). Current theories therefore fail to account for confabulations as they appear in schizophrenia.

However, Kopelman (1999) has been reluctant to acknowledge that schizophrenia patients can have true confabulations. He points out that Nathaniel-James and Frith (1996)'s comparison with Kopelman (1987) was not justified as some of the amnesic patients did reorganize and reconstruct the original story and states that "confabulations" (quotation marks are his) in schizophrenia are momentary intrusion errors and distortions, resulting from faulty memory and delusional beliefs (Kopelman, 1999). While Kopelman has been right in pointing out that the tendency to reorganize and restructure the original information may not be unique to schizophrenia, several studies, using various paradigms, have shown that schizophrenia patients present with confabulations no less complex or severe than those found in any other condition (Kraepelin, 1971; Kramer et al., 1998; Lorente-Rovira et al., 2007; Lorente-Rovira et al., 2010; McKenna, 2007; Salazar-Fraile et al., 2004; Simpson \& Done, 2002).

Few studies have examined confabulation in schizophrenia and the paradigms used tend to be relatively simple, often not exceeding a few sentences (e.g., fables). No study to date has investigated confabulations using paradigms that contain a larger amount of information. 
Although such an approach would present methodological challenges - controlling for memory deficits found in schizophrenia patient recall, establishing a reliable method to analyze the narrative, etc.- - investigating confabulations using longer narrative tasks (e.g., videos) may more closely mimic the nature of autobiographical memories. There is some indication that performance of schizophrenia patients on longer narrative tasks (like story recall) differs from their performance on word/sentence recall tasks. For instance, schizophrenia patients tend to restructure and reorganize information in fables (Nathaniel-James \& Frith, 1996). It is not known whether they would do the same if they were shown (e.g.) a movie, especially due to the larger demands placed on memory, and due to their limited cognitive resources (executive functioning, working memory, etc.) (Belzeaux et al., 2011).

\section{Cognition}

A wide range of cognitive deficits have been associated with confabulations (Benson et al., 1996; Cunningham, Pliskin, Cassisi, Tsang, \& Rao, 1997; Kopelman et al., 1997; Turner et al., 2010). Despite some overlap, the cognitive correlates of schizophrenic confabulations differ from those seen in other conditions and include temporal context confusion, incoherence of speech, formal thought disorder, and semantic memory impairment (Lorente-Rovira et al., 2007; Nathaniel-James et al., 1996).

Though memory deficits have been often observed in neurological patients with confabulations, schizophrenic confabulations are often not associated with memory impairment (Kramer et al., 1998; Morais et al., 2004; Nathaniel-James \& Frith, 1996; Nathaniel-James et al., 1996). Several studies have shown that memory deficits are neither necessary nor sufficient for confabulation to occur in schizophrenia (Lorente-Rovira et al., 2007; Lorente-Rovira et al., 2010; Nathaniel-James et al., 1996; Nathaniel-James \& Frith, 1996; Salazar-Fraile et al., 2004). 
Moreover, schizophrenia patients confabulate on narrative tasks which do not involve a memory component (Kramer et al., 1998), suggesting that schizophrenic confabulations are only in part a result of retrieving erroneous and insufficient ideas from memory.

Lee et al. (2009) found that patients with Alzheimer's disease show more confabulations on episodic than semantic memory. Possible explanations for this include greater task demands placed by episodic retrieval (semantic memory often does not require retrieval of time information). Semantic memory confabulations were associated with atrophy of the anterior cingulate, medial and middle temporal gyri while episodic confabulations, which were more common among delusional patients, were associated with lower prefrontal blood flow, suggesting that the two kinds of confabulations have different neural substrates. Other studies have described patients with episodic (but not semantic) confabulation (Dalla Barba et al., 1990; La Corte et al., 2011). Most laboratory investigations assess provoked semantic confabulations (for methodological reasons) but not much research attention has been devoted to understanding the relation between these two types of false memories.

Studies on the role of executive functions in schizophrenic confabulations have produced inconsistent results. While some studies have found an association with executive function, response monitoring and response suppression, others have not (Gurd, 1995; Lorente-Rovira et al., 2007; Lorente-Rovira et al., 2010; Nathaniel-James et al., 1996; Nathaniel-James \& Frith, 1996). Studies have also failed to find an association of schizophrenic confabulations with planning, IQ, or verbal fluency impairments (Lorente-Rovira et al., 2007; Nathaniel-James \& Frith, 1996; Nathaniel-James et al., 1996; but see Morais et al., 2004; Salazar-Fraile et al., 2004). Taken together, these findings suggest that the association of executive functions with confabulations is not as well established in schizophrenia as in neurological conditions (e.g., 
Moscovitch \& Melo, 1997). Even in non-psychotic populations, confabulators have been described who lack clear executive deficits (Dab, Claes, Morais, \& Shallice, 1999; DelbecqDerouesne, Beauvois, \& Shallice, 1990). As noted above, the findings from schizophrenia do not support the retrieval theory view that memory and executive deficits alone combine to cause confabulations (Baddeley \& Wilson, 1998); for review, see (DeLuca, 2000). The retrieval account seems to apply better, though not invariably, to neurological conditions (Lorente-Rovira et al., 2007). On the other hand, a case can be made that schizophrenic confabulations are uniquely associated with language deficits in schizophrenia

Present evidence from schizophrenia does not lend unequivocal support to any of the cognitive mechanisms implicated by the various theories that account for confabulations. It can be hypothesized that the cognitive deficits implicated by the most popular theory at present (strategic retrieval) might also play a role in schizophrenic confabulations, but it is not known what the relative contributions of these deficits (e.g., memory, executive deficits) are and what role other cognitive/metacognitive deficits (source-monitoring, temporal context confusion, etc.) may play in schizophrenic confabulations.

\section{Language}

Schizophrenia patients tend to produce more memory errors on stories than on word lists (see Nathaniel-James \& Frith, 1996), unlike brain damaged patients, who do poorly on both (Dab et al., 1999; Delbecq-Derouesne et al., 1990). They also exhibit difficulty in distinguishing plausible from implausible information in fables, but not in functional sentences like "the old man has a branch for a walking stick" (Nathaniel-James \& Frith, 1996; Nathaniel-James et al., 1996). This suggests that confabulations may in part be the result of poor comprehension and organizational ability which may affect the encoding process, and manifest as errors at retrieval. 
Morais et al. (2004) showed that confabulation in schizophrenia patients was higher for fables than stories, and higher for stories than word lists. Schizophrenic confabulations are also found to be associated with conceptual disorganization (Salazar-Fraile et al., 2004). These findings suggest that verbal comprehension deficits during encoding may contribute to the production of confabulations in schizophrenia.

Some studies have suggested a specific role for semantic memory deficits in schizophrenic confabulations. Lorente-Rovira et al. (2007) found a clear difference between confabulators and non-confabulators on semantic memory tasks like the semantic verification test [which requires true/false responses to sentences, e.g., 'Buses are driven', 'Geese have 4 legs' (Laws, Evans, Hodges, \& McCarthy, 1995)], and the Camel and cactus test [which involves matching a target word (camel) to a related word from a set (tree, sunflower, cactus, rose) (Bozeat, Lambon Ralph, Patterson, Garrard, \& Hodges, 2000)] (Lorente-Rovira et al., 2010). Schnider and colleagues (1996) found a positive association of verbal fluency with provoked confabulations. They suggest that a partial explanation for this could be that both memory recall as well as verbal fluency tasks demand actively searching one's memory. In people with defective memory, better search strategy may result in increased item recollection (verbal fluency) as well as higher number of confabulations. However, the mechanisms underlying the association of verbal fluency with confabulation are not well understood and their association is not unequivocally supported (Cunningham et al., 1997).

\section{Formal thought disorder and communicative disturbance}

Nathaniel-James and Frith (1996) found that formal thought disorder (e.g., tangential thinking, loose associations) was associated with the severity (though not presence) of confabulation in schizophrenia (Lorente-Rovira et al., 2007; Lorente-Rovira et al., 2010; 
Nathaniel-James \& Frith, 1996; Nathaniel-James et al., 1996). Schizophrenia patients with formal thought disorder sometimes generate idiosyncratic/bizarre statements that are indistinguishable from fantastic confabulations of neurological patients in content, and in the fact that they are often unprovoked (Kopelman et al., 1997; Laws et al., 1995; Lorente-Rovira et al., 2007; Nathaniel-James \& Frith, 1996). E.g., McKenna and Oh (2005) describe a patient (from Chaika, 1974) who stated that his mother's name was Bill, Valentine's Day was the official start of the breeding season for birds, and buzzards coo.

Lorente-Rovira et al. (2007) have argued that reorganizing and reconstructing ideas within a story to produce new information may not be very different from derailment in formal thought disorder. Also, the tendency of confabulating schizophrenia patients to commit errors like referring to a voyage as a swimming expedition (Nathaniel-James and Frith, 1996) is similar to the use of word approximations seen in thought disorder (Lorente-Rovira et al., 2007). Given the fact that the evidence for a central role of executive deficits in schizophrenic confabulations is weak, they suggest that schizophrenic confabulations may, instead, involve a defective strategic retrieval system interacting with defective semantic memory (Lorente-Rovira et al., 2010). The importance of semantic memory in schizophrenia may only be relative. Semantic memory impairments also contribute to neurological confabulations, though more to their characteristics (e.g., bizarreness) than their presence (Dalla Barba, 1993a; Dalla Barba, 1993b).

However, the important difference between formal thought disorder and confabulation is that the former is associated with the disorganization (form) of speech while the latter pertains to the veracity of its content. Confabulations (e.g., Baddeley \& Wilson, 1988; Kopelman, 1987) involve errors of content, not form. Thought disorder involves abnormalities in word use, disorganized syntax and failure to integrate sentences; such linguistic abnormalities are not found 
in neurological confabulations (for discussion see Lorente-Rovira et al., 2007). That said, it can often be difficult to determine in clinical settings whether a patient's speech is demonstrating a disorder of form or content, or both.

It is possible that confabulations may also be related to measures of communication deficit like the communication disturbance index (CDI; see Docherty, DeRosa, \& Andreasen, 1996). Though the CDI is related to measures of formal thought disorder (Docherty \& Gordinier, 1999), it measures the failures in transmission of meaning from the speaker to the listener rather than deficits in the form of speech (Docherty, Cohen, Nienow, Dinzeo, \& Dangelmaier, 2003). One type of CDI — the missing information reference (CDI-MIR) — may be especially relevant to confabulations. Missing information reference involves referring to information not previously presented and not known to the listener (e.g., a patient may say "some of those shops were filthy" despite no prior mention of any shops during the conversation) (see Docherty et al., 2003). While some missing references may be more parsimoniously attributed to omission errors, it is possible that some missing references may be the result of false memories that the speaker holds, which may be the case especially for shared experiences. If this is true, we would expect to observe higher rates of missing information references in confabulating patients, though this has not yet been empirically investigated. Another reason to expect an association of CDI-MIR to confabulation is its association with source monitoring (Nienow \& Docherty, 2005) which some studies have shown to be associated with confabulations (Gilboa \& Verfaellie, 2010; Turner et al., 2010). Though higher rates of CDI-MIR in schizophrenia patients may not conclusively be attributable to the presence of false memories, finding such an association can pave the way for future research including follow up interviews to determine the nature of the missing references. 
Though there is evidence of an association of language deficits, formal thought disorder, semantic memory and verbal fluency with schizophrenic confabulations, the nature of this relation has not been fully explored and no concrete theories have been proposed to account for them. Confabulation may also be related to communication disturbances but no studies so far have investigated it. The association of verbal comprehension, semantic memory and formal thought disorder with confabulation raises the possibility that linguistic processes may play a significant, though not at present well-understood, role in schizophrenic confabulations.

\section{Delusions}

A delusion is a false belief firmly sustained despite evidence to the contrary, not culturally explicable, and usually preoccupying (American Psychiatric Association, 1994; Kopelman, 2010). A confabulation, on the other hand, is a false memory where the person is not aware of its falsehood. Both phenomena share phenomenological similarities including falseness, conviction, resistance to disconfirming evidence (Kopelman, 2010), and persistence, which led early theorists to consider confabulations a part of delusions (Korsakoff, 1891; see Berrios, 2000).

While confabulation in other neuropsychiatric conditions is often viewed and investigated as an isolated phenomenon, schizophrenic confabulations are closely related to other features of the condition. Simpson and Done (2002) found that delusional schizophrenia patients confabulate significantly more than non-delusional patients and non-psychiatric controls. They found that the occurrence of confabulations is affected by the presence of a relation between encoded information and the content of delusions, whereas delusion related schemas affect the way information is incorporated into memory. Salazar-Fraile and colleagues (2004) found schizophrenic confabulations to be related only to conceptual disorganization, but not other symptoms. However, in patients with non-schizophrenic psychosis, they found an association 
with delusions and grandiosity as well. The evidence from schizophrenia at present suggests that delusions and other positive symptoms are associated with, but do not cause, confabulation (Nathaniel-James \& Frith, 1996; Simpson \& Done, 2002; also see (Salazar-Fraile et al., 2004). There are several similarities (and some important differences) between delusions and confabulations:

Delusions are known to be consistent over time, while confabulations are usually not. A patient may report, at various times, that he is in the hospital because he was attacked by enemy aircraft, has problems with his leg, and was bitten by a rabbit, never repeating any of the claims (Turner \& Coltheart, 2010). But there are cases where confabulations are stable over time, like patients who wake up every morning and dress for work (e.g., Burgess \& McNeil, 1999). Some authors have attributed the observed lack of consistency in confabulation to memory deficits in these patients, and note that improvements in memory result in confabulations becoming more delusion-like in terms of consistency (Turner \& Coltheart, 2010).

Delusions (by definition) tend to be associated with conviction, and resistance to counterarguments. Confabulations are associated with severe memory deficits, but evidence suggests confabulators tend to show conviction for the memories they have at any given time (see Langdon \& Bayne, 2010; Turner \& Coltheart, 2010). Confabulating patients will defend their claims and even generate additional false memories to support them (e.g., McKenna, 2007). Conviction in confabulating patients is partly attributable to their tendency to perseverate. When confabulating patients are confronted with the truth, they tend to cling on to their fallacy by perseverating (Moscovitch, 1989). Confabulators also tend to make increased perseverative errors on objective measures like the WCST (Ciaramelli, Ghetti, Frattarelli, \& Làdavas, 2006; Fischer, Alexander, D'esposito, \& Otto, 1995; Moscovitch, 1989; Moscovitch \& Melo, 1997) and 
perseveration decreases with decline in confabulation (Kapur \& Coughlan, 1980; see Asp \& Tranel, 2013). In summary, though conviction is not a defining feature of confabulation, evidence suggests that confabulations are often associated with conviction. However, we don't have sufficient empirical evidence to determine whether there are differences in the level of conviction associated with delusion versus confabulation.

Delusions may range from believing that people are watching the patient (delusions of reference) to believing that aliens are removing one's thoughts (thought withdrawal). Similarly, confabulations may range from claiming that one is still employed and has to get to work (Burgess \& McNeil, 1999) to claiming that another person has a bee's head (Turner et al., 2010); so, both confabulations and delusions can vary from the commonplace to bizarre.

Confabulations and delusions do not share the same neural substrates. While confabulations are consistently associated with lesions to the prefrontal cortex (Johnson \& Raye, 2000; Moscovitch \& Winocur, 2002; Parkin, 1997; Schnider, Bonvallat, Emond, \& Leemann, 2005; Stuss et al., 1978) and especially the orbitofrontal cortex (OFC) and medial PFC (Moscovitch, 1989; Schnider, 2003), the neural substrates of delusions are not well understood. Studies have implicated many different brain regions (Menon et al., 2011; Spence et al., 1997; Zwanzger, Ella, Keck, Rupprecht, \& Padberg, 2002) but there does not seem to be a clear overlap in the neural substrates of these two phenomena.

Gilboa (2010) found that memory deficits, context confusion, and monitoring deficits, which were associated with confabulations, were not associated with delusions. The relation between delusion and cognitive deficits has been equivocal (Jeste, Wragg, Salmon, Harris, \& Thal, 1992; Kopelman, 2010; Selva et al., 2007) and when memory deficits are present in delusion, they are related to biased encoding of novel information (Gilboa, 2010). Confabulation 
on the other hand (at least in neurological patients) has often been associated with amnesia and almost invariably with executive dysfunction (see Kopelman, 2010) and is best viewed as primarily a disorder of retrieval (Gilboa \& Verfaellie, 2010). Finally, delusions are often more elaborate, systematic and pervasive than confabulations (Kopelman, 1999).

While some confabulating patients do act on their beliefs (Christodoulou, 1977; Burgess \& McNeil, 1999; Schnider, 2008), confabulations do not result in actions as commonly as delusions. However it must be noted that delusional patients do not always act on their beliefs either (see Langdon \& Bayne, 2010), a view even Bleuler (1950) subscribed to:

"Kings and Emperors, Popes and Redeemers engage, for the most part, in quite banal work...None of our generals has ever attempted to act in accordance with his imaginary rank and station." (p. 129).

On the other hand, some confabulating patients do act on their beliefs (Christodoulou, 1977; Burgess \& McNeil, 1999; Schnider, 2008). However, this is relatively less common in confabulation than delusions (though this may perhaps be attributable to fewer studies having investigated confabulations).

There have been different views on the relation between confabulations and delusions:

- Berrios (2000) suggest that confabulation is a form of delusion when delusion is broadly defined.

- Turner and Coltheart (2010) suggest that delusions and confabulations share common origins. They propose that a failure of some processes results in the formation of an implausible idea, and failure of others results in the acceptance of these ideas as true, suggesting that the same mechanism can account for both delusions and confabulation.

- Kopelman (Kopelman et al., 1995; Kopelman, 1999) suggests that delusions and 
confabulations are distinguishable based on etiology. He argued that confabulations are found in neurological disorders, and delusions are found in psychiatric illnesses.

- Hirstein (2005) argues that delusions are false beliefs, while confabulations are false claims, so they cannot be classified together. This view is also supported by Mattioli (Mattioli, Miozzo, \& Vignolo, 1999) who showed that delusions and confabulations have different courses and evolutions. However, there may be cases where delusions result in confabulation, e.g., Capgras delusion (Hirstein, 2005).

None of the above theories fully account for the similarities and differences between confabulation and delusion mentioned earlier. The cognitive and neural differences do not support the views (Berrios, 2000; Turner \& Coltheart, 2010) that confabulation and delusions are the same, or the result of common mechanisms, while the phenomenological similarities between the two symptoms do not support the view (Hirstein, 2005) that delusions and confabulations are entirely separable. Kopelman's (1999) distinction (based on etiology) is not particularly useful given current evidence that delusions are also found in neurological illnesses (Fricchione, Carbone, \& Bennett, 1995) and confabulations in psychiatric populations (Nathaniel-James \& Frith, 1996; (Salazar-Fraile et al., 2004).

The current evidence seems to suggest that confabulations and delusions are distinct phenomena which share certain characteristics, though we do not fully understand what the cognitive and neuropsychological bases of their intriguing similarities are. However, there are two cases where delusions and confabulations are virtually indistinguishable--delusional memory and delusional confabulation. Delusions can originate from various sources. They can arise 'out of the blue' (autochthonous delusion), from a normal or abnormal perception (like hallucinations), affective changes (delusional mood), or memory (delusional memory). Of these, 
only delusional memory pertains largely to memory processes.

Delusional memory is commonly defined as a delusion that arises from a (usu. episodic) memory (for alternate definitions, see Kopelman, 2010). These delusional interpretations may have their origin in a true, or false, memory. A delusion resulting from a false memory is indistinguishable from confabulation. For example, a patient may remember undergoing an operation as a child and become convinced he has been implanted with a controlling and monitoring device (Semple \& Smyth, 2005).

Delusional confabulations are a rare phenomenon in which fantastic delusions and delusional memories are made up on the spot and shift, change and become more elaborate as the patient is questioned about them (McKenna, 2007). McKenna describes a schizophrenic patient with hallucinations and catatonic symptoms (but no current delusions) who reported that he was shot and went to work the next morning with a hole in his head (see McKenna, 2007). One of our patients A.P, a 48 year old African-American male with schizophrenia, showed evidence of delusional confabulation during a routine interview. In response to questioning, he generated secondary confabulations. At the time of interview he did not meet criteria for delusions, and showed poor memory and some confabulation on a semantic memory task [Wechsler Logical memory-IV (Wechsler, 1945)]. Due to significant thought disorder (tangentiality, loosening of association) the patient had to be asked specific questions to keep him on the topic. However, the following day, he repeated the confabulations with very little change (see Shakeel \& Docherty, 2014):

E: How many children do you have?

P: I may have over a 100 children.

E: How many children do you know by name? 
P: My son, he is pretty big, he is 8 feet tall and $650 \mathrm{lbs}$. and he killed a man called [name of gigantic pro-wrestler]...the wrestler

E: How did he kill him?

P: He probably crushed his skull.

E: Why did he kill him?

P: Because the wrestler...tried to rape my mom.

E: What happened after...that?

P: Yeah, I don't know what happened though. I don't know if he did time for that. He probably had a hell of a lawyer.

E: Where did this happen?

P: I don't know. Probably in Ohio somewhere.

E: How often do you meet (your son)?

P: I never met him. I have seen him on magazine...seen him on T.V. I've seen him on T.V. as the Predator.

E: You said you had a 150 children, how you know...

P: They told me, when I had pneumonia I was taken to the hospital, before I got discharged they said we took your blood a 100 times. 'A hundred times!' I said, 'why?', I don't know.

E: And what did they do with that blood?

P: I don't know, I guess maybe they want to try to know how many kids I have got. And they tried to take more blood. But I won't let them.

E: And why are they interested in taking your blood and finding out how many children you have? 
P: (Because) my children want to know who their father is.

Unlike delusions, confabulations do not always pertain to beliefs. When a patient looks out the window and tells the examiner that his (the examiner's) boat has been stolen (Stuss et al., 1978) or confabulates on the Anna Thompson story (Kern, Van Gorp, Cummings, Brown, \& Osato, 1992) and Aesop fables (Nathaniel-James \& Frith, 1996), there is no obvious element of delusion involved. Only confabulations which affect personal beliefs can be considered delusional, the significant example being delusional memory and delusional confabulations. We cannot always distinguish a confabulation ('a microchip was implanted in my head') from a belief ('I believe a microchip was implanted in my head') as there is no corresponding external reality which allows us to do so. Therefore delusions and confabulations are best viewed as separable phenomena which may be present simultaneously in rare cases like delusional confabulations and some kinds of delusional memory because these are simultaneously false memories as well as false beliefs. As the vast number of papers devoted to resolving the issue (see Langdon \& Turner, 2010) suggests, at present there is no agreement on how best to conceptualize the relation between delusions and confabulations.

Another way of conceptualizing the relation between delusions and confabulations emerges from the studies which investigate the relation between normal beliefs and memories (see for e.g., Mazzoni \& Kirsh, 2002). In this view, confabulations can be conceptualized as a special class of delusions which pertain to memory the same way that memories are considered a special class of beliefs. Delusions can refer to any false belief (e.g., persecutory, referential, grandiose, etc.) with false beliefs about memory being one of them. Although this may be a new theory given our current definitions for delusion and confabulation, it must be noted that this not an entirely new way of thinking. Some of the earliest thinkers like Korsakoff conceptualized 
delusions sufficiently broadly to incorporate within it the idea of false memories (see translation by Victor \& Yakovlev, 1955). In fact, as Berrios (1998) points out, the problem of the relation between confabulations and delusions only arose after the $1910 \mathrm{~s}$, with the introduction of the rigid Jasperian criteria (later incorporated into the DSM) arbitrarily narrowing down the concept of delusion (see Berrios \& Fuentenbro, 1996).

The relation between delusion and confabulation has been the subject of a great deal of debate recently (see Langdon \& Turner, 2010). Few papers have looked at the association between confabulation and delusion specifically in schizophrenia. To approach this question in schizophrenia research we need to firstly investigate the co-occurrence of delusion and confabulation in schizophrenia. Then, we can investigate the cognitive/metacognitive deficits associated with these two phenomena (esp. in patients who have both). This may not only inform us about delusion and confabulation in schizophrenia, but also provide useful hypotheses about their relation in other neuropsychiatric conditions.

\section{Present Study}

The present study aims to investigate the features and mechanisms of confabulations in schizophrenia. To do this we utilized a confabulation paradigm which was developed by Chrobak and Zaragoza (e.g., Chrobak \& Zaragoza, 2008) originally for use in a non-psychiatric population (college undergraduates). The paradigm involves viewing a 20 minute video, responding to suggestive questions about events in the video, and assessing recall of the story at various time points over 8 weeks (for detailed description see under methods section 'Development of the Confabulation Paradigm').

- Week 0: Participants watch a video, which has segments missing from two scenes. 
- Week 1: The participants are asked to describe what happens during each scene. They are also asked to guess what might have happened during the missing segments (forced fabrication).

- Week 2: The participants' responses are read out to them.

- Week 8: In the free recall session, participants are asked to recollect what happens in the entire movie, followed by a cued recall session where they are asked for details from each scene.

The week 8 interviews were coded for:

- Confabulation elements (elements): Number of occurrences where a new physical/verbal action occurs.

- Confabulation instances (instances): Number of elements (false physical/verbal actions) which are related in some temporal/causal manner.

- Fabricated elements: Number of elements of confabulation for scenes which had segments missing.

- Non-fabricated elements: Number of elements of confabulations for scenes which did not have any segments missing.

- True memory: Checklist based assessment of number of true physical/verbal actions recalled from the original story.

- Temporal context confusion: Number of true events recalled in the wrong context

- Repeated elements: Number of fabricated elements present at week 1 which were also recalled at week 8 .

Information about symptoms and cognitive functioning was also collected. The paradigm and assessments were administered to patients with schizophrenia as well as a group of healthy 
control participants.

We were interested in investigating whether schizophrenia patients show evidence of confabulations when tested using this paradigm, and whether their confabulations differ quantitatively and qualitatively from those of healthy control participants. We also wanted to assess the cognitive/metacognitive correlates of confabulations in schizophrenia to evaluate the various theories which account for confabulations. We also wanted to assess the relation of confabulations to language and formal thought disorder. Finally, we wanted to assess the relation between confabulations and positive symptoms to determine the nature of their relation in schizophrenia.

\section{Hypotheses and rationale}

1. Schizophrenia patients will generate more confabulation elements than healthy controls Rationale: Schizophrenia patients have the candidate cognitive/metacognitive deficits various theories implicate in the formation of confabulations and are hence more susceptible to confabulate.

2. Schizophrenia patients will generate more confabulation instances than healthy controls. Rationale: Schizophrenic confabulations are characterized by a unique tendency to create subnarratives and causally/temporally link disparate elements of a narrative to present a coherent story (Nathaniel-James \& Frith, 1996).

3. Schizophrenia patients will confabulate on fabricated as well as non-fabricated events more than healthy controls, who will confabulate mostly on the fabricated events.

Rationale: To test the prediction that the gap-filling account applies better to healthy control participants than schizophrenia patients. 
4. Schizophrenia patients, when compared to healthy controls, will remember fewer of their fabricated confabulations from week 1 at week 8 .

Rationale: Memory deficits in schizophrenia may affect not only their memory for true information, but also for false information they were compelled to generate (sneak/prank events). 5. Confabulation in schizophrenia will be associated with poor memory and executive function more than with source monitoring (SM) deficits. Confabulations will also be associated with temporal context confusion.

Rationale: To test the cognitive and metacognitive mechanisms implicated by the Strategic retrieval (amnesia/defective memory + executive deficits) and Source monitoring theory (internal SM \& external SM) simultaneously. This will allow us to determine which of the competing theories can best account for schizophrenic confabulations (The strategic retrieval account has strongest support in neurological studies, so we hypothesize a priori that it will be significant in schizophrenia as well). We also wanted to assess the temporality theory by assessing whether temporal context confusions (TCC) are associated with the presence of confabulations. As TCCs are a feature of, as well as a mechanism implicated in confabulations, we examined the association between TCC and confabulation in a separate analysis.

6. Confabulations will be associated with missing information references (CDI-MIR), formal thought disorder (FTD), and semantic fluency.

Rationale: Though they are not causally related to each other, missing information reference and confabulations may both result from poor source monitoring. Confabulations may contribute to the severity of missing information references in some settings, esp. for shared knowledge and experiences. Some studies have shown schizophrenic confabulations are associated with FTD, verbal comprehension, semantic memory, and verbal fluency, and we wanted to systematically 
investigate the role of these factors. Generalized (cognitive and psychopathological) deficit can be controlled for by using block-wise regression.

7. Positive symptom severity will be associated with severity of confabulations.

Rationale: Confabulation may (in part) be the result of positive psychopathology in

schizophrenia, in which case it will be associated with the presence and severity of delusions and hallucinations (after controlling for severity of general psychopathology) 


\section{Methods}

\section{Participants}

The sample consisted of outpatients with a DSM-IV diagnosis of schizophrenia or schizoaffective disorder $(n=67)$ and healthy control participants $(n=23)$ matched to the patients on age, gender, race/ethnicity, and parental education (see Table 1) who were part of a larger NIH grant funded project examining emotion, neurocognition, and communication disturbance (Grant number 5R01-MH58783; see (Docherty et al., 2003; Shakeel \& Docherty, 2012). Only patients aged between 15-50 years, who spoke English as a primary language, and met DSM-IV criteria for schizophrenia or schizoaffective disorder were included in the sample. The Schedule for Affective Disorders and Schizophrenia_-Lifetime Version (Endicott \& Spitzer, 1978), adapted slightly for use with DSM-IV criteria, was used to arrive at the DSM diagnosis. Patients were excluded if they reported a history suggestive of possible organic brain damage such as illness or head injury resulting in prolonged loss of consciousness, met criteria for mental retardation, had a history of seizures/epilepsy, underwent alcohol detoxification, or met DSM-IV criteria for current (past year) substance abuse. All patients (except one) were receiving psychiatric medications at the time of the study. The study was carried out with due approval of the Kent State University Institutional Review Board, and informed consent was obtained from all participants prior to enrollment in the present study.

\section{Procedure}

Information from the patients was collected over a period of 8 weeks. Participants were given $\$ 50$ for every session they attended and were allowed to discontinue anytime they wanted. 
The confabulation data were collected as described below. Other details about symptoms, and cognitive functions were also collected during these sessions.

\section{Measures}

\section{Development of the confabulation paradigm}

Previous studies of confabulation have investigated it using relatively simple paradigms like pictures or fable recollection tasks (e.g., Lorente-Rovira et al., 2007; 2010; Nathaniel-James and Frith, 1996; Schnider, 2003) which often fail to capture subtle aspects of elaborate confabulations which patients can produce. We adapted a specific paradigm (developed by Chrobak \& Zaragoza, 2008) to analyze confabulations in schizophrenia which involved testing over a period of 8 weeks.

Week 0: In the first session, participants are asked to watch a 20 minute Disney video of two brothers at a summer camp as part of an experiment to observe "how adults understand the events they see" (incidental learning paradigm). Most of the scenes are continuous segments of the movie and describe events involving the two brothers (Sullivan and Delaney), interacting with each other and with others, and performing various actions at the camp. The original Disney movie was edited such that there are important segments missing from two scenes. In the Prank scene, Delaney stands up to make an announcement and falls in the dining hall. The scene does not show what caused him to fall. In the Sneak scene, two people are shown sneaking off in a canoe. The scene does not show where they go or what they do and skips to the next scene. Week 1 Interview: The participants are given brief prompts about each scene and are asked to describe as fully as they can what happens during that scene. They are also asked to "recall" segments of the Prank and Sneak scenes that were not actually presented. If the participant says 
he/she is not able to recall what happens during the Prank/Sneak scene, they are encouraged to give their best guess (forced fabrication). The participants are asked to provide information about

- What happened?

- Where did it happen?

- With whom/who was involved?

- What did they do?

Week 2 Recognition test: The participants' interview responses for each scene (at week 1) are read out to them verbatim. Then they are asked whether they remember seeing the events described, and if they remember discussing them during the interview at week 1 . For scenes that the participants failed to describe at week 1, a brief summary of what occurred in the actual movie during that scene is described and the participant is asked whether they remember seeing and/or discussing it.

Week 8 Free and cued recall: Participants have a free recall session where they are asked to recall as much of the movie as possible (with no questions/feedback from the investigator). This is followed by a cued recall session where they are given brief prompts (e.g., "The next scene takes place in the dining hall. Tell me anything you remember about that part of the movie") and asked for details from each scene. For coding purposes, the distinction between free and cued recall was ignored and the entire transcript for week 8 (free + cued recall) was used.

Sessions at week 1 and 8 were audio recorded, transcribed, crosschecked, and then the coding scheme was implemented (for more details of the coding scheme and complete memory checklist, see Appendix 1: Confabulation Coding Scheme). In brief, every transcript at week 8 was coded for:

Confabulation elements (elements): Number of occurrences where a new physical/verbal action 
occurs. For example, the participant may say "his brother drowned" or "the lady said she wanted to show her friends the camp" (though neither of these actions occurred in the movie). Each new physical/verbal action is counted as one element.

Confabulation instances (instances): Number of elements (false physical/verbal actions) which are related in some temporal/causal manner. E.g., the following actions (none of which actually occur in the movie) are all related in a temporal/causal manner and so are coded as an instance containing 4 elements.

- Instance 1 (Ratface's mischief). Elements:

○ "Ratface put a banana peel on the dining floor"

○ "Ratface gets caught."

○ "Chief (who thinks Delaney was responsible) gets ready to get rid of him"

○ "Chief finds out the truth and apologizes to Delaney".

Instances are only coded when there is a causal/temporal relation between elements. When elements are unrelated to each other, they are coded as separate elements. In the present analysis, number of elements that formed instances were added to compute the total instance score (e.g., if a participant generates 2 instances with 3 and 6 elements each, total instance score equals 9). Fabricated elements: Number of elements of confabulation for scenes which had segments missing ('Sneak' and 'Prank' scene). These are coded the same way elements and instances are, but they are analyzed separately because the investigator made the participant generate this information (at week 2)

- Example: Forced fabrication (Prank scene) (one instance with 2 elements)

- Instance 1: (Delaney falls). Elements

- "Ratface messes with the chair on which Delaney stood" 
- "The chair breaks and Delaney falls"

Non-fabricated elements: Number of elements of confabulations for scenes which did not have any segments missing (i.e. for all scenes other than 'Sneak' and 'Prank"). These are coded the same way elements and instances are, but these confabulations were generated spontaneously by the participant and not prompted by the investigator.

True memory: Checklist based assessment of number of accurate physical/verbal actions recalled from original story. This is coded based on participant responses in free recall and cued recall phases of the week 8 interview.

Temporal context confusion: Number of true events recalled in the wrong context (e.g., recalling an event in scene 4 as having happened during the opening scene).

Repeated elements: Number of fabricated elements present at week 1 which were also recalled at week 8. (Note: Repeated elements are the only case where information from week 1 is analyzed. For all other variables, only information from week 8 is used).

\section{Cognitive/metacognitive measures}

Internal Source Monitoring: Internal source monitoring refers to the ability to discriminate between internally generated sources of information (Johnson et al., 1993). An internal source monitoring (SM) task we previously developed (Nienow \& Docherty, 2004) was used for the present study. Briefly, participants have to generate single word responses to 16 incomplete statements. The statements are ones for which there is only one appropriate response (e.g., "The first month of the year is "). On half the trials the subjects only think of the answer to themselves, and on the other half they say the answer out loud. Immediately after this, they are given a source recognition sheet with all the responses they said, thought, and with eight new words (total of 24 words), and they have to identify whether they had said or thought each 
word on the list, or if the word was new. The task was piloted on 39 college students, who showed $99 \%$ agreement on the words they used to complete the statements. To derive a source monitoring score after controlling for recognition memory, the discrimination ratio [(say or think correct)/ old correct] was calculated for the present analysis.

External Source Monitoring: External source monitoring refers to the ability to discriminate between externally generated sources of information (Johnson et al., 1993). For the external source monitoring task, participants have to listen to an audio recording of 12 statements, half of which are said by a female voice and half by a male voice (presented in a quasi-random order). Immediately after the presentation, the participants have to indicate whether each statement was said by the man or woman, or if it was new (see Docherty, 2012). To derive a source monitoring score after controlling for recognition memory, the discrimination ratio [(man or woman correct)/ old correct] was calculated for the present analysis.

Executive function: There have been differences of opinion regarding the nature and components of executive function (see Donohoe \& Robertson, 2003). However, most conceptualizations involve elements of volition, planning, purposive action, self-regulation, and effective performance (Lezak, 2004). A computerized version of the Wisconsin Card Sorting Test (WCST; Berg, 1948) was used to derive a measure of perseverative errors. The participant is shown four stimulus cards - 1 red triangle, 2 green stars, 3 yellow crosses, and 4 blue circles. The participant is then presented with 64 cards which she has to place, one by one, under the stimulus cards according to a principle she has to deduce from the program's responses ("right" or "wrong") to each placement. The principle (sort by color, sort by shape, and sort by number) changes after every 10 correct placements. Perseverative errors occur when the participant continues to sort the cards according to an erroneous guess or a previously successful principle. 
Perseverative errors provide an assessment of the capacity for planning, and effective performance. It also reflects the capacity for self-regulation, concept formation, conceptual flexibility, and profiting from correction (Lezak, 2004). Though no single test at present assesses all aspects of executive functions, perseverative errors provide an assessment of the capacity for self-regulation and effective performance, which most closely resembles the aspects of executive function significant for the strategic retrieval theories [ability to monitor and reject/suppress inaccurate information (see Gilboa \& Moscovitch, 2002; Moscovitch \& Melo, 1997)]. The standard score of total perseverative errors (which demographically corrects for age and education) was used for the present analysis.

Communication Disturbance Index-Missing Information Reference (CDI-MIR): Communication deficit was assessed using the CDI-MIR (Docherty et al., 1996). Participants provided a speech sample approximately $10 \mathrm{~min}$ in length on topics like self-perceptions, interests, and daily activities, which was then coded to derive the number of missing information references, which involves referring to information not previously presented and not known to the listener (Docherty et al., 2003). Errors are only counted if they result in confusion or obscuring the meaning of the utterance. To control for differences in amount of speech generated across participants, CDI-MIR ratings are computed as the number of instances of missing information reference per 100 words of speech.

Semantic fluency: The verbal fluency test requires the participant to generate (in one minute) as many words as possible belonging to a specific category. It assesses the participant's ability to carry out semantic search and retrieval, and the ability to switch between categories (see Lezak, 2012). The total correct score on a semantic fluency test (for animal names) was used in the present study. 
Shipley Institute of Living Scale-I (Shipley, 1940; Zachary \& Shipley, 1986): The Shipley derived IQ score is highly correlated with the Wechsler Adult Intelligent Scale-Revised full scale IQ score (Frisch \& Jessop, 1989). For the present study we used the verbal section of the test, which is known to provide an accurate estimation of premorbid verbal intelligence (Shipley, 1940; Zachary \& Shipley, 1986).

\section{Symptom ratings}

PANSS-CD: Severity of positive, negative, general, and total symptoms were rated using the Positive and Negative Syndrome Scale (Kay, Flszbein, \& Opfer, 1987). The PANSS is completed by the interviewer and rates the patient on a scale of 0 (absent) to 7 (extreme) on severity of positive (delusions, hallucinations, conceptual disorganization, etc.), negative (blunted affect, emotional/social withdrawal, difficulty in abstract thinking, etc.) and general psychopathology symptoms (anxiety, depression, disorientation, attention deficit, lack of insight, etc.). For the present analysis we use the PANSS conceptual disorganization score as an index of formal thought disorder.

BPRS: The Brief Psychiatric Rating Scale (Overall \& Gorham, 1962) provides a measure of general psychopathology (Nuechterlein, Edell, Norris, \& Dawson, 1986). It allows the interviewer to rate the patient on severity (ranging from 'not present' to 'extremely severe') of somatic concerns, guilt, suspiciousness, grandiosity, motor retardation, suicidality, self-neglect, uncooperativeness, etc. The BPRS total score [minus item-11 (Conceptual Disorganization)] was used as a measure of general psychopathology when analyzing the relation between formal thought disorder/language related variables and confabulations (hypothesis 6). When analyzing the relation between positive symptoms and confabulation, BPRS [minus items 6-9 (delusions and hallucination)] was used (hypothesis 7). 
PSYRATS: The Psychotic Symptom Rating Scales (PSYRATS) (Haddock, McCarron, Tarrier, \& Faragher, 1999) is a more elaborate measure of delusions and hallucination than PANSS and BPRS. The PSYRATS covers a range of features including frequency, duration, distress, loudness, controllability, beliefs about hallucinations etc. and preoccupation, conviction, distress, disruption (etc.) caused by the presence of delusions. Current hallucination severity was calculated by adding the scores on duration, loudness and frequency of hallucinations (see Docherty, 2012). Each of these variables is coded on a scale of 0-4 where higher scores reflect worse hallucinations, allowing for a total score of 12 for hallucinations having the greatest severity. Severity of current delusions was also assessed using the PSYRATS. The scoring is similar to that of hallucinations, except that there are 6 questions on delusion severity (with a maximum possible score of 24).

\section{Interrater reliability for confabulation coding scheme}

The IRR analysis (Intraclass correlation coefficient), based on two independent raters using the coding scheme to rate 5 transcripts ( 3 schizophrenia patients and 2 healthy controls) showed the following IRR scores.

- $\quad$ Total elements $=.85$

- Elements $($ free recall $)=.90$

- Elements $($ cued recall $)=.94$

- Memory code $=.81$

\section{Power Analysis}

A-priori analyses were conducted using G*Power 3 (Faul, Erdfelder, Lang, \& Buchner, 2007). When power was specified at a level of $0.8(p<.05)$, needed total sample size for hypotheses were: 
- Hypothesis 1: $n=84$

- Hypothesis 2: $n=84$

- Hypothesis 3: $n=24$

- Hypothesis 4: $n=84$

- Hypothesis 5: $n=48$

- Hypothesis 6: $n=54$

- Hypothesis 7: $n=48$

As we anticipated a total sample size of 90, with 67 schizophrenia patients and 23 healthy controls, we anticipated having adequate statistical power for our planned analyses.

\section{Data analysis plan:}

\section{Data cleaning and preparation}

- Number of true memories generated was significantly different between the groups and could not be used as a covariate (Table 2). Healthy participants generated significantly more true memories than the patient group. They also generated more total memory (true

+ false memory) than the patient group. To control for differences in total memory (which increases the probability of both true and false memories) first a total memory score was computed [true memory + false memory (elements)] for the transcripts.

- To control for differences in total memories generated, elements, instances, fabricated and non-fabricated elements were expressed in terms of percentage of total memory for the between group analyses. These were labeled element percent, instance percent, fabricated element percent, and non-fabricated element percent, respectively (hypotheses $1-4)$. 
- For the schizophrenia group analyses (hypotheses 5-7), elements and CDI-MIR had to be $\log$ transformed to normalize distribution.

- One univariate outlier each was excluded from the fabricated element and repeated elements percent variable (hypothesis $3 \& 4$ ).

\section{Analysis: Hypotheses}

1. Schizophrenia patients will generate more confabulation elements than healthy controls. Methods: Between group t-test

- IV: Group (schizophrenia/healthy controls)

- DV: Element percent.

2. Schizophrenia patients will generate more confabulation instances than healthy controls. Methods: Between group t-test

- IV: Group (schizophrenia/healthy controls)

- DV: Instance percent.

3. Schizophrenia patients will confabulate for fabricated as well as non-fabricated events more than healthy controls, who will confabulate mostly on the fabricated events.

\section{Method: MANOVA}

- $\quad \mathrm{IV}=$ Group (schizophrenia/healthy controls)

- $\quad \mathrm{DV}=$ Fabricated element percent, Non-fabricated element percent.

4. Schizophrenia patients, when compared to healthy controls, will remember fewer of their fabricated confabulations from week 1 at week 8 .

Methods: Between group t-test

- IV: Group (schizophrenia/healthy controls)

- DV: Repeated elements. 
5. Confabulation in schizophrenia will be associated with poor memory recall and executive function more than with source monitoring (SM) deficits. Confabulations will also be associated with temporal context confusions.

Method: Multiple linear regression

- $\mathrm{IV}=$ True memory, WCST perseverative errors (standard score), internal SM (discrimination ratio) and external SM (discrimination ratio)

- $\mathrm{DV}=$ Elements $(\log )$.

- Correlation between temporal context confusion and elements $(\log )$.

6. Confabulations are associated with missing information references (CDI-MIR), formal thought disorder, and semantic fluency.

Method: Block wise regression

Block-1:

- IV: Shipley's Institute of living vocabulary score, true memory, BPRS total score (minus conceptual disorganization)

- DV: Elements $(\log )$.

Block-2:

- IV: CDI-MIR $(\log )$, PANSS conceptual disorganization, semantic word generation total score

- DV: Elements $(\log )$.

7. Positive symptom severity is associated with severity of confabulations.

Method: Sequential linear regression

Block 1:

- IV: BPRS total score (minus delusion and hallucination score) 
- DV: Element $(\log )$

Block 2:

- IV: PSYRATS hallucination severity, PSYRATS delusion severity

- DV: Elements $(\log )$. 


\section{Results}

\section{Socio-demographic details}

The sample consisted of 67 schizophrenia patients and 23 healthy control participants (Table 1). The mean age for patients was 42.97 years $(\mathrm{SD}=8.08)$ and controls $39.95(9.84)$ years. Both groups had close to $50 \%$ women. The groups significantly differed on level of education [patients $=11.60(1.78) ;$ controls $=15(2.22)]$, however they were closely matched on parental education $[$ patients $=11.31(3.14)$; controls $=12.02(1.88)]$. A significantly larger percentage of patients were unemployed (54\% vs 13\%), and patients also had a significantly lower score on the global assessment of functioning scale [(46.85 (13.98) vs 84.60 (8.26)]. Both groups had roughly equal percentage of African Americans/mixed African American and Caucasian ethnicity (patients $=62.69 \%$; controls $=61 \%$ ). Approximately half the patients were diagnosed with DSM-IV schizophrenia; the rest were diagnosed with schizoaffective disorder (depressive or bipolar type). One third of schizophrenia patients were diagnosed with the paranoid subtype, with the rest diagnosed as disorganized or undifferentiated subtypes. Table 2 provides the means and standard deviations for all confabulation variables and memory. Complete data was available for the between group analyses for 60 schizophrenia participants and 19 healthy control participants.

\section{Tests of Hypotheses}

Hypothesis 1: Between-group t-test showed schizophrenia patients generated a significantly higher percentage of confabulation elements $(M=36.80, S D=19.14)$ compared to healthy controls $(M=24.17, S D=12.22)[t(47.67)=-3.39, p<.01]$. The difference represents a medium 
effect size $(d=.71)$. (See Table 2; Figure 1).

Hypothesis 2: Between group t-test showed schizophrenia patients generated a significantly higher percentage of confabulation elements that were related to each other (confabulation instances $)(M=23.96, S D=22.38)$ compared to healthy controls $(M=14.85, S D=14.21)[t$ $(47.95)=-2.10, p<.05]$. The difference represents a medium effect size $(d=.62)$. (See Table 2 ; Figure 1).

Hypothesis 3: Using Pillai's trace, there was a significant effect of group on number of fabricated and non-fabricated confabulation element percents $[V=.08, F(2,76)=3.50, p<.05]$. Separate univariate ANOVAs on the outcome variables revealed significant group effects for non-fabricated confabulation element percent $[F(1,77)=6.57, p<.05$, partial eta squared $=$ $.08]$, but not for fabricated confabulation elements percent $[F(1,77)=0.55, p>.05$, partial etasquared $=.01]$. In other words, schizophrenia patients generated higher percentages of confabulation elements $(M=27.51, S D=17.38)$ which did not involve suggestive questioning, compared to healthy controls $(M=16.53, S D=11.93)$ (see Table 2; Figure 1).

Hypothesis 4: A between group t-test showed schizophrenia patients reproduced fewer of the fabricated confabulations generated at week 1 at week $8(M=0.84, S D=1.16)$ compared to healthy controls $(M=1.58, S D=1.35)[t(78)=2.35, p<.05]$ (Table 2$)$. The difference represented a medium effect size $(d=.61)$. Follow up analysis showed that when number of repeated elements were expressed as a percentage of number of confabulation elements (repeated element percent), the groups continued to show a trend $[t(78)=1.94, p=.056, d=-0.51]$. In other words, repeated confabulations constituted a greater part of confabulation elements of healthy controls $(M=22.36, S D=19.25)$ when compared to patients $(M=13.20, S D=17.57)$.

Hypothesis 5: Means and Standard deviation of the patients for elements (log), temporal 
context confusion, true memory, WCST, internal and external source monitoring are shown in Table 3. Using the patient sample, correlations were computed between elements (log) and temporal context confusions. The results showed that temporal context confusion had a significant positive correlation with elements $(\log )(r=.29, p<.05)$. However, correlations between elements (log) and true memory, WCST perseverative errors (standard score), internal source monitoring, and external source monitoring were not significant (Table 4).

Multiple Linear regression with true memory, WCST perseverative errors (standard score), internal source monitoring, and external source monitoring as predictors (entered simultaneously using forced entry method) and elements (log) as dependent variable did not result in a significant final model $[F(4,51)=0.72, p>.05)$ (Table 5). Follow up analysis was carried out with separate regressions of cognitive functions implicated by retrieval theory (true memory and WCST) on element (log), and source monitoring theory (internal and external source monitoring) on elements (log), but neither resulted in a significant predictive model.

Hypothesis 6: Using the patient sample, correlations were computed between elements (log) and Shipley's vocabulary score, true memory, BPRS, CDI-MIR, PANSS and verbal fluency test (VFT) (Table 6; for means and standard deviations see Table 3). Of these, there was a significant positive correlation between elements $(\log )$ and CDI-MIR $(r=.24, p<.05)$, and PANSS conceptual disorganization $(r=.27, p<.05)$. There were no significant correlations between elements (log) and Shipley's vocabulary score, true memory, BPRS, or VFT.

In block 1 of sequential regression analysis, regression of Shipley’s vocabulary score, true memory, and BPRS on elements $(\log )$ did not result in a significant predictive model $[F(3,45)=$ $0.53, p>.05]$. In block 2, when CDI-MIR, semantic verbal fluency, and PANSS conceptual disorganization were included simultaneously (forced entry method), there was no significant 
change in the model $[F$ change $(3,42)=2.18, p>.05]$ and the final model (Table 7$)$ remained non-significant $[F(6,42)=1.37, p>.05]$. Follow up analyses where Shipley's vocabulary score, true memory, and BPRS were entered in block 1, but CDI-MIR, semantic verbal fluency and PANSS conceptual disorganization were introduced individually in block 2 in separate regression analyses showed non-significant results.

Hypothesis 7: Correlations were computed between elements (log) and BPRS, PSYRATS hallucination, and PSYRATS delusion (Table 8; for means and standard deviations see Table 3). There was a significant correlation between PSYRATS delusion and elements $(\log )(r=-.26)$, but the correlation between elements (log) and hallucination was not significant.

Sequential regression analysis with BPRS (minus items which code for delusions and hallucinations) as the predictor in Block 1 did not result in a significant predictive model of confabulations elements $(\log )\left[F(1,41)=.01, p>.05 ; R=0.01, R^{2}=.00\right]$. When PSYRATS hallucinations and PSYRATS delusions were included in block 2 (using forced entry method) there was a significant change in the model $[F$ change $(2,39)=5.54, p<.01]$ and the final model was also significant $[F(3,39)=3.70, p<.05 ; R=.47]$. The final model accounted for $22 \%$ of the variance in confabulation elements $(\log )\left[R^{2}=.22\right]$. (Table 9$)$. The coefficients of both predictors were significant (Hallucination $B=.04($ Beta $=.44), t(39)=2.71, \mathrm{p}<.05$; Delusion $B$ $=-.03($ Beta $=-.49), t(39)=-2.98, p<.01]$. 


\section{Discussion}

\section{Summary of Findings}

Healthy control participants generated a significantly higher number of true memories than schizophrenia patients. When compared to healthy control participants, schizophrenia patients generated a significantly higher percentage of confabulation elements and instances. Schizophrenia patients also generated a significantly higher percentage of confabulation elements which were not induced by suggestive questioning and repeated fewer of their fabricated confabulation elements from week 1 at week 8 .

Correlational analysis between confabulation elements and temporal context confusion, true memory, executive functioning, internal source monitoring, and external source monitoring found that temporal context confusions were positively correlated with confabulation elements. However, when true memory, executive functioning, internal source monitoring, and external source monitoring were combined in a regression analysis, it did not result in a significant predictive model of confabulation elements.

Correlational analysis showed that there was a significant positive correlation of confabulation elements with missing information references and formal thought disorder. However, a regression analysis showed that missing information references, formal thought disorder, and verbal fluency did not result in a significant predictive model of confabulation elements (after controlling for premorbid verbal intelligence, true memory, and general psychopathology severity).

Finally, correlational analysis of confabulation elements with delusions and hallucinations showed that severity of delusions was negatively correlated with confabulation elements. After 
controlling for severity of psychopathology, severity of delusions and hallucinations resulted in a significant predictive model of confabulation elements. While hallucinations were positively associated with confabulation elements delusions were negatively associated with them.

\section{Interpretation of Findings}

\section{Schizophrenia patients generate more confabulation elements and instances than}

\section{healthy controls}

To control for significant differences in true memory, confabulations elements and instances were expressed as percentages of total memory (true + false memory). In agreement with previous studies (Lorente-Rovira et al., 2007; Lorente-Rovira et al., 2010; Nathaniel-James \& Frith, 1996; Nathaniel-James et al., 1996), the current study found that schizophrenia patients generated a significantly higher percentage of false memories than healthy control participants. Patients also generated a higher percentage of false memory elements that were related to each other in some causal/temporal manner (instances) than healthy controls. However, quantitative analyses fail to adequately capture the more intriguing qualitative aspects of schizophrenic confabulations:

Theme: Firstly, schizophrenia patients tended to diverge from the original narrative more than healthy control participants did. While control participants often satisfied the gap-filling theory and generated brief commission errors in order to present a coherent story ["(Delaney)...pulled the ladies back in" (the ladies were actually helped by other counselors)], patients tended to recall events that had no relevance to the story ["Sullivan and Delaney went fishing, then Sullivan fell off the boat...they were both saved by another person from the camps"]. Patients generated stories with themes as varied as a diamond heist, Sullivan dying, 
Delaney having smoking and drinking problems, there being an award ceremony, etc., none of which were required to complete the original story. We did find some evidence to support the view (Nathaniel-James \& Frith, 1996) that schizophrenia patients tend to reorganize and restructure the original story rather than generate something completely new [unlike patients suffering from neurological conditions (Kopelman, 1987)] and that confabulations are often constrained by the context of the original information (Lorente-Rovira et al., 2007). Patients often borrowed characters and events from the original story when confabulating. For example, one patient combined elements from the scene where Delaney kills a snake when giving the ladies a tour of the lake and Sullivan being pushed into the water by Ratface and his friends, to present a story in which:

Sullivan was in the boat [no ladies present]... (he) jumped over the edge of the boat. Delaney....apprehended (sic) the snake... (and) threw the snake over. Sullivan (swam) over and got in the boat with another camper. Delaney was upset... (and said) he thought Sullivan should have stayed in the boat. He would have got (sic) the snake.

However, completely unrelated confabulations are indistinguishable from formal thought disorder (which the coding scheme excludes e.g., "Mike Tyson bit someone's ear", though it rarely occurred in the transcripts). So evidence from the current study only partially supports the theory that schizophrenic confabulations are constrained by the elements and context of the original information.

Subnarratives: Nathaniel-James and Frith (1996) first noted the unique tendency of schizophrenia patients to reorganize and restructure the original story, which resulted in changing the 'sense' of the original information (Nathaniel-James et al., 1996). When they were asked to recall Aesop fables which were presented to them, they not only provided erroneous 
recollections, but also failed to extract the moral or gist of the original story. However, all previous studies of confabulation have used relatively simple tasks like recollecting Aesop fables (which typically consist of around 5 sentences) or pictures (e.g., Lorente-Rovira et al., 2007; Nathaniel-James \& Frith, 1996; Schnider, 2003). We were interested in knowing how this tendency to confabulate might manifest in a more complex task (20 minute audio-visual clip tested over 8 weeks using an incidental learning paradigm). The present study is the first to demonstrate that schizophrenia patients tend to digress and create subnarratives within their recollection of the original story rather than to reorganize the entire original story. For example (Sneak scene):

Delaney and Sullivan (went to) see the girls. They might have been drinking or something. (The boat tipped over and) Sullivan fell into the water. They had to swim back to the shore. The little boy got sick from that. The little boy laying (sic) on the bed and Delaney was next to him and they were talking. Sullivan...died.

Another example:

(The Chief) left the chow hall early 'cause he didn't like (Delaney). (He thought he was) gonna try to take his job or something, so he trying (sic) to get him out of the way....and then he went down the river dock...he put a snake on the boat and then nobody even knowed (sic) that he did it but I did...' cause he knew (Delaney) had to take some people out on the boat.

It is likely that patients create subnarratives because restructuring an entire 20 minute audio-visual clip would demand significant cognitive resources, but it is hard to account for why patients create subnarratives (that don't serve any functional purpose) in the first place. It does not serve a gap-filling function, nor can it be accounted for entirely in terms of confusing the 
order of information (temporality theory). It may be related to retrieving erroneous information and failing to reject it (strategic retrieval theory) but that does not account for the formation of organized clusters of false memories. These subnarratives—like subplots in a bad Hollywood movie - are often unrelated to, and do very little to support the original story and the reason for their existence remains (to borrow Jasper's description of primary delusions) "ununderstandable" (Jaspers, 1963, p. 96).

Confidence: Healthy control participants tended to have less conviction in their false memories compared to schizophrenia patients. Some level of uncertainty often accompanied their false memories ("I am assuming that (the snake) had bitten the guy earlier and it had gotten away. It crawled into the canoe"; "It seems as if someone pulled a chair...I think someone moved a piece of furniture (causing Delaney to fall)". Though not invariably, patients tended to lack this sense of uncertainty ("(In the dining hall) Ratface wanted some of (Sullivan's) food, matter of fact I know he did cause he went over to his table..."; "I am pretty sure...Delaney's little brother...tricked Ratface into coming down there”; "(The chief)...put that snake on the boat and then nobody knowed (sic) that ...but I did."). This tendency for schizophrenia patients to generate false information and then hold on to it with greater conviction than healthy participants (known as "knowledge corruption") has been demonstrated previously (Moritz, Woodward, Whitman, \& Cuttler, 2005).

\section{Schizophrenia patients generate more non-fabricated confabulations than healthy}

\section{controls}

At week 0 , schizophrenia patients as well as healthy controls were shown scenes which had segments missing ("Sneak" and "Prank") as well as scenes which did not. At week 1, both groups were asked to recall the details from each scene, and were asked to "guess" what might 
have happened during the missing segments (fabricated elements). At week 8 , when they were asked to recall the events in the original movie, schizophrenia patients generated a significantly higher percentage of confabulations for scenes which did not have any segments missing (nonfabricated elements) compared with controls. However, the groups did not significantly differ on the number of false memories generated for scenes which did have segments missing (fabricated elements). Our findings provide further evidence against the popular view (American Psychiatric Association, 1994; Kraepelin, 1971; Mercer et al., 1977; Semple \& Smyth, 2005) that patients confabulate to fill-in gaps in their memory or avoid embarrassment.

\section{Schizophrenia patients remember fewer of the fabricated confabulations generated}

\section{at week 1 at week 8}

There is no agreement in the literature over whether confabulations are a result of encoding or retrieval processes (Fotopoulou, 2010; Gilboa \& Moscovitch, 2002; Kramer et al., 1998; Nathaniel-James \& Frith, 1996). The present study found that although schizophrenia patients generated significantly more confabulations than healthy controls at week 8 , they recollected significantly fewer of their fabricated elements from week 1 at week 8 . This pattern of findings does not support the encoding view which would have predicted that erroneous information generated at week 1 would later be recollected as confabulations at week 8 . Our

findings suggest that patients (esp.) tended to generate false memories spontaneously at week 8 rather than relying on recollecting false memories they generated earlier. Hence, our findings partially support the strategic retrieval view which suggests that confabulations are a result of failures in retrieval processes rather than encoding deficits.

\section{Schizophrenic confabulations and cognitive functions}

No systematic investigation of the cognitive correlates of confabulation has been 
previously reported in a schizophrenia population. We hypothesized, based on the evidence from neurological conditions, that schizophrenic confabulations would also be associated primarily with memory and executive function impairment. We found that true memory, executive functioning, internal and external source monitoring did not significantly predict confabulations. Our findings in this regard fail to support the source monitoring theory as well as the retrieval theory. In terms of the cognitive functions implicated by the retrieval theory (memory deficits and executive functioning) our findings suggest that schizophrenic confabulations, unlike confabulations in neurological patients, are not strongly associated with memory impairments (Kramer et al., 1998; Lorente-Rovira et al., 2007; 2010; Morais, Frith, \& Dab, 2004; NathanielJames \& Frith, 1996; Nathaniel-James et al., 1996; Salazar-Fraile et al., 2004).

The evidence in previous studies for executive function impairments is mixed, with some studies showing a relation between executive function and confabulations in schizophrenia, and others not (Gurd, 1995; Lorente-Rovira et al., 2007; Lorente-Rovira et al., 2010; NathanielJames \& Frith, 1996; Nathaniel-James et al., 1996). Our study failed to find a significant role for executive functions in confabulation. Though it is hard to draw conclusions from negative findings, our results, when interpreted along with other studies which have investigated executive functions in schizophrenic confabulations (Gurd, 1995; Lorente-Rovira et al., 2007; Lorente-Rovira et al., 2010; Nathaniel-James \& Frith, 1996; Nathaniel-James et al., 1996), suggest that executive dysfunction may not be as central to the formation of confabulations in schizophrenia as the it is in neurological patients (e.g., Moscovitch \& Melo, 1997).

This is the first study to investigate the role of source monitoring in schizophrenic confabulations, and after controlling for recognition memory, we found no evidence to support a role for internal or external source monitoring deficits in schizophrenia (also see Ciaramelli \& 
Ghetti, 2007, Johnson et al., 1997). Despite the theoretically plausible relation between source monitoring and confabulations the evidence is mixed even in neurological studies. While some studies have shown an association of source monitoring deficits with confabulation (Turner et al., 2010), others have not (Ciaramelli \& Ghetti, 2007, Johnson et al., 1997).

Temporal context confusions (TCC) were not included in the regression analysis as the tendency to recall information in the wrong context may be categorized as a factor underlying as well as a characteristic of confabulation (see e.g., Schnider, 2003) (though our analysis only coded TCC as the former). We found a significant positive correlation between temporal context confusion and confabulation, suggesting that confusing the order of information may play a role in some schizophrenic confabulations. While it must be noted that not all confabulations are conceptually related to confusing the order of information (Christodoulou, 1977; McKenna, 2007; Turner et al., 2010) narratives from our patients suggest that at least some confabulations may be the result of confusing the order of information, and then trying to provide a coherent story by introducing additional elements. For example, one patient confused events in the opening scene with the dining hall scene and stated that they were all gathered for a picnic. The patient then went on to state that they had "...hot dogs, egg salad, potato salad, French fries and...I think a cup of... hot chocolate...I think (one kid) dropped his cup or somebody threw some food on him". Although everyone is gathered outside in the opening scene, and Delaney does knock over some food when he falls in the dining hall scene, none of the mentioned food items appear anywhere in the movie. While healthy controls, regardless of memory for details, often tended to reproduce the gist of the narrative in the correct temporal order, patients tended to confuse the scenes in which specific events occurred and this may have partially contributed to the generation of confabulations. 


\section{Schizophrenic confabulations, formal thought disorder and missing information}

\section{references}

Previous studies from schizophrenia and neurological conditions have suggested that formal thought disorder and semantic dysfluency may play a role in schizophrenic confabulations (Lorente-Rovira et al., 2007; Nathaniel-James \& Frith, 1996; Schnider et al., 1996). However these studies failed to adequately control for variables like premorbid IQ, true memory, and general psychopathology. We controlled for these factors and found that missing information references, formal thought disorder and semantic fluency did not result in a significant predictive model of confabulations. However, when correlations were analyzed, there was a significant positive correlation of confabulations with missing information references and formal thought disorder, suggesting that linguistic problems like an inability to keep track of what the listener has already been told and failure to organize speech in a coherent manner may partially contribute to the generation of confabulations (also see Salazar-Fraile et al., 2004). Our findings provide partial evidence to suggest that disorders of the form and content of speech may be more closely linked than previously suspected. However, further studies are required to investigate the nature of this relation.

\section{Schizophrenic confabulations and positive symptoms}

The present study found that delusions and hallucinations significantly predicted confabulations (after controlling for severity of psychopathology). While the regression coefficients of hallucinations suggested a positive association with confabulations, severity of delusions was negatively associated with them.

While this is the first study to find a specific relation between hallucination severity and confabulations in schizophrenia, a few studies have previously investigated the relation between 
delusions and confabulation in schizophrenia, with mixed results. While Salazar-Fraile et al. (2004) found schizophrenic confabulation was related to conceptual disorganization but not other positive symptoms, Simpson and Done (2002) found that delusional schizophrenia patients confabulate more than non-delusional schizophrenia patients.

However, there are important differences between delusions and hallucinations from a cognitive perspective that might be relevant to our findings. It has been shown that psychotic patients with hallucinations exhibited higher metacognitive dysfunction than delusional patients (Morrison \& Wells, 2003), presence of hallucinations (but not delusions) in Alzheimer's patients was associated with more rapid cognitive decline (Wilson, Gilley, Bennett, Beckett, \& Evans, 2000) and the presence of delusions in dementia patients was associated with relative preservation of mental function (Berrios \& Brook, 1985). Moreover, while theories of hallucination often implicate cognitive/metacognitive deficits (Johnson et al., 1993), major theories of delusions do not (Kapur, 2003; Maher, 1974). While not conclusive, taken together the evidence suggests the possibility that severity of delusions reflects relatively better preserved cognitive functioning, and the significant negative association between confabulation and delusions (and positive association between confabulation and hallucinations) in our study may be because patients with more confabulations have worse cognitive functioning. However, we have previously analyzed the major cognitive deficits implicated by current theories of confabulation and failed to find an association with most of them. It remains possible that schizophrenic confabulations are associated with other cognitive functions not implicated by data from neurological patients.

When patient A.P was interviewed again several months later, he was asked how many children he had: 
P: I don't have no children that I know of.

E: Okay, but last time...you told me...you had many children.

P: I really don't know. That was...part of my delusion or something...

Whether in the minds of sufferers or researchers, the nature of relation between delusions and confabulation continues to elude us.

\section{Conclusions and Future Directions}

Schizophrenia patients generated more confabulations than healthy control participants. They differed from healthy control participants in their tendency to create confabulations that were causally/temporally related to each other, to confabulate on scenes which did not have any missing segments or suggestive questioning, and to fail to recollect previously generated confabulations. Qualitatively, schizophrenia patients generated confabulations that were further removed from the original story than healthy controls' confabulations, they created subnarratives that were mostly irrelevant to the original story, and tended to show more confidence in their recollections. Schizophrenic confabulations were associated with confusing the order of given information, missing information references, and positive symptoms like formal thought disorder, hallucinations and delusions. While hallucinations were associated with increased confabulation, delusions were associated with decreased confabulation scores.

Two main conclusions can be drawn from our present study and review. First, schizophrenic confabulations differ from those of healthy controls and have their own unique characteristics i.e., they are not simply an extension of normal commission errors of memory. Second, schizophrenic confabulations cannot be accounted for in terms of current theories of confabulation. While we found some evidence to suggest a role for temporality errors, there was 
no evidence to support source monitoring and gap-filling accounts, and the lack of support for the strategic retrieval theory is in stark contrast to the large number of studies of neurological patients which strongly support it.

An argument can be made that confabulation in schizophrenia behaves more like a symptom than a cognitive phenomenon. While we did not find sufficient evidence to support our theory that confabulations are a special class of delusions, we found that confabulations were associated with formal thought disorder, delusions (negatively) and hallucinations. Also, similar to other schizophrenia symptoms, while confabulations do have cognitive correlates, they cannot be fully accounted for by them.

Given that we have established that the tendency to confabulate has a significant effect on the schizophrenia patient's mental process in an experimental setting, future research should investigate the effect of these confabulations on a patient's day to day life. It is possible, as Bleuler (1950) observed about his delusional patients, that confabulating patients learn to ignore their false memories in the real world setting and, though endlessly fascinating to the psychopathologist, their confabulations have a minimal effect on their day to day lives. It is also possible that confabulations do interfere with the patient's real world functioning and contribute to social, occupational and interpersonal dysfunction. If so, then confabulations deserve a lot more attention than is currently given to them. 


\section{Bibliography}

Alexander, M. P. (2011). Confabulation. In B. Levine, \& F. I. Craik (Eds.), Mind and the frontal lobes: Cognition, behavior, and brain imaging (pp. 16-32). USA: OUP.

American Psychiatric Association. (1994). Diagnostic and statistical manual of mental disorders. (4th ed.). Washington D.C.: American Psychiatric Publishing, Inc.

Asp, E., \& Tranel, D. (2013). False tagging theory. In D. T. Stuss, \& R. T. Knight (Eds.), Principles of frontal lobe function (2nd ed., pp. 383-416). New York: Oxford University Press.

Baddeley, A., \& Wilson, B. (1988). Amnesia, autobiographical memory, and confabulation. In D. Rubin (Ed.), Autobiographical memory (pp. 225-252). New York: Cambridge University Press.

Bajo, A., \& Kopelman, M. D. (2008). Ongoing reality monitoring versus mood state in determining confabulation. Poster presented at the first meeting of the federation of European neuropsychological societies.

Belzeaux, R., Ibrahim, E., Fakra, E., Adida, M., Cermolacce, M., \& Azorin, J. (2011). Schizophrénie, génétique et cognition. L'Encéphale, 37, S127-S132.

Benson, D., Djenderedjian, A., Miller, B., Pachana, N., Chang, L., Itti, L., \& Mena, I. (1996). Neural basis of confabulation. Neurology, 46(5), 1239-1239. 
Berg, E. A. (1948). A simple objective technique for measuring flexibility in thinking. The Journal of General Psychology, 39(1), 15-22.

Berlyne, N. (1972). Confabulation. The British Journal of Psychiatry, 120(554), 31-39.

Berrios, G., \& Brook, P. (1985). Delusions and the psychopathology of the elderly with dementia. Acta Psychiatrica Scandinavica, 72(3), 296-301.

Berrios, G. E. (1998). Confabulations: A conceptual history. Journal of the History of the Neurosciences, 7(3), 225-241.

Berrios, G. E. (2000). Confabulations. In G. E. Berrios, \& J. R. Hodges (Eds.), Memory disorders in psychiatric practice (pp. 348-368). Cambridge: Cambridge University Press.

Berrios, G. E., \& Fuentenebro, F. (1996). Delirio: Historia, clinica, metateoria. Madrid: Trotta.

Bleuler, E. (1950). Dementia praecox or the group of schizophrenias. New York: International Universities Press.

Bonhoeffer, K. (1904). Der korsakowsche symptomenkomplex in seinen beziehungen zu den verschiedenen krankheitsformen. Allgemeine Zeitung Psychiatrie, 61, 744-752.

Bonhoeffer, K. (1901). Die akuten geisteskrankheiten der gewohnheitstrinker: Eine klinische studie. Jena: Fischer.

Bozeat, S., Lambon Ralph, M. A., Patterson, K., Garrard, P., \& Hodges, J. R. (2000). Non-verbal semantic impairment in semantic dementia. Neuropsychologia, 38(9), 1207-1215. 
Burgess, P. W., \& McNeil, J. E. (1999). Content-specific confabulation. Cortex, 35(2), 163-182.

Chaika, E. (1974). A linguist looks at "schizophrenic" language. Brain and Language, 1(3), 257276.

Christodoulou, G. (1977). The syndrome of capgras. The British Journal of Psychiatry, 130(6), $556-564$.

Chrobak, Q. M., \& Zaragoza, M. S. (2008). Inventing stories: Forcing witnesses to fabricate entire fictitious events leads to freely reported false memories. Psychonomic Bulletin \& Review, 15(6), 1190-1195.

Ciaramelli, E., \& Ghetti, S. (2007). What are confabulators' memories made of? A study of subjective and objective measures of recollection in confabulation. Neuropsychologia, 45(7), 1489-1500.

Ciaramelli, E., Ghetti, S., Frattarelli, M., \& Làdavas, E. (2006). When true memory availability promotes false memory: Evidence from confabulating patients. Neuropsychologia, 44(10), $1866-1877$.

Conway, M. A., \& Tacchi, P. C. (1996). Motivated confabulation. Neurocase, 2(4), 325-339.

Cunningham, J. M., Pliskin, N. H., Cassisi, J. E., Tsang, B., \& Rao, S. M. (1997). Relationship between confabulation and measures of memory and executive function. Journal of Clinical and Experimental Neuropsychology, 19(6), 867-877.

Dab, S., Claes, T., Morais, J., \& Shallice, T. (1999). Confabulation with a selective descriptor 
process impairment. Cognitive Neuropsychology, 16(3-5), 215-242.

Dalla Barba, G. (1993a). Confabulation: Knowledge and recollective experience. Cognitive Neuropsychology, 10(1), 1-20.

Dalla Barba, G. (1993b). Different patterns of confabulation. Cortex, 29(4), 567-581.

Dalla Barba, G., Cipolotti, L., \& Denes, G. (1990). Autobiographical memory loss and confabulation in Korsakoff's syndrome: A case report. Cortex, 26(4), 525-534.

Dalla Barba, G., \& Decaix, C. (2009). "Do you remember what you did on March 13, 1985?" A case study of confabulatory hypermnesia. Cortex, 45(5), 566-574.

Dalla Barba, G., Mantovan, M. C., Cappelletti, J. Y., \& Denes, G. (1998). Temporal gradient in confabulation. Cortex, 34(3), 417-426.

Damasio, A. R., Graff-Radford, N. R., Eslinger, P. J., Damasio, H., \& Kassell, N. (1985). Amnesia following basal forebrain lesions. Archives of Neurology, 42(3), 263-271.

Delbecq-Derouesne, J., Beauvois, M., \& Shallice, T. (1990). Preserved recall versus impaired recognition: A case study. Brain, 113(4), 1045-1074.

DeLuca, J. (2000). A cognitive neuroscience perspective on confabulation. Neuropsychoanalysis, 2(2), 119-132.

Docherty, N. M. (2012). Missing referents, psychotic symptoms, and discriminating the internal from the externalized. Journal of Abnormal Psychology, 121(2), 416-423. 
Docherty, N. M., Cohen, A. S., Nienow, T. M., Dinzeo, T. J., \& Dangelmaier, R. E. (2003). Stability of formal thought disorder and referential communication disturbances in schizophrenia. Journal of Abnormal Psychology, 112(3), 469-475.

Docherty, N. M., DeRosa, M., \& Andreasen, N. C. (1996). Communication disturbances in schizophrenia and mania. Archives of General Psychiatry, 53(4), 358-364.

Docherty, N. M., \& Gordinier, S. W. (1999). Immediate memory, attention and communication disturbances in schizophrenia patients and their relatives. Psychological Medicine, 29(1), 189-197.

Donohoe, G., \& Robertson, I. (2003). Can specific deficits in executive functioning explain the negative symptoms of schizophrenia? A review. Neurocase, 9(2), 97-108.

Faul, F., Erdfelder, E., Lang, A., \& Buchner, A. (2007). G* power 3: A flexible statistical power analysis program for the social, behavioral, and biomedical sciences. Behavior Research Methods, 39(2), 175-191.

Fischer, R. S., Alexander, M. P., D'esposito, M., \& Otto, R. (1995). Neuropsychological and neuroanatomical correlates of confabulation. Journal of Clinical and Experimental Neuropsychology, 17(1), 20-28.

Fotopoulou, A. (2010). The affective neuropsychology of confabulation and delusion. Cognitive Neuropsychiatry, 15(1-3), 38-63.

Fricchione, G. L., Carbone, L., \& Bennett, W. I. (1995). Psychotic disorder caused by a general medical condition, with delusions. Secondary "organic" delusional syndromes. The 
Psychiatric Clinics of North America, 18(2), 363-378.

Frisch, M. B., \& Jessop, N. S. (1989). Improving WAIS-R estimates with the shipley-hartford and wonderlic personnel tests: Need to control for reading ability. Psychological Reports, 65(3), 923-928.

Gilboa, A. (2010). Strategic retrieval, confabulations, and delusions: Theory and data. Cognitive Neuropsychiatry, 15(1-3), 145-180.

Gilboa, A., Alain, C., Stuss, D. T., Melo, B., Miller, S., \& Moscovitch, M. (2006). Mechanisms of spontaneous confabulations: A strategic retrieval account. Brain, 129(6), 1399-1414.

Gilboa, A., \& Moscovitch, M. (2002). The cognitive neuroscience of confabulation: A review and a model. In A. Baddeley, M. Kopelman \& B. Wilson (Eds.), Handbook of memory disorders (1st ed., pp. 315-342). New York: Wiley.

Gilboa, A., \& Verfaellie, M. (2010). Introduction—-telling it like it isn't: The cognitive neuroscience of confabulation. Journal of the International Neuropsychological Society, 16(06), 961-966.

Gurd, J. (1995). Frontal dissociations: Evidence from Parkinson's disease. Journal of Neurolinguistics, 9(1), 55-68.

Haddock, G., McCarron, J., Tarrier, N., \& Faragher, E. (1999). Scales to measure dimensions of hallucinations and delusions: The psychotic symptom rating scales (PSYRATS). Psychological Medicine, 29(04), 879-889. 
Hashtroudi, S., Johnson, M. K., Vnek, N., \& Ferguson, S. A. (1994). Aging and the effects of affective and factual focus on source monitoring and recall. Psychology and Aging, 9(1), 160-170.

Hirstein, W. (2005). Brain fiction: Self-deception and the riddle of confabulation. Massachusetts: The MIT Press.

Jeste, D. V., Wragg, R. E., Salmon, D. P., Harris, M. J., \& Thal, L. J. (1992). Cognitive deficits of patients with Alzheimer's disease with and without delusions. The American Journal of Psychiatry, 149(2), 184-189.

Johnson, M. K., \& Raye, C. L. (2000). Cognitive and brain mechanisms of false memories and beliefs. In D. L. Schacter, \& E. Scarry (Eds.), Memory, brain, and belief (pp. 35-86). Cambridge, MA: Harvard University Press.

Johnson, M. K., Hashtroudi, S., \& Lindsay, D. S. (1993). Source monitoring. Psychological Bulletin, 114(1), 3-28.

Johnson, M. K., Hayes, S. M., D'Esposito, M., \& Raye, C. L. (2000). Confabulation. In L. Cerman (Ed.), Handbook of neuropsychology (2nd ed., pp. 383-407). Amsterdam: Elsevier Science Publishers BV.

Johnson, M. K., O'Connor, M., \& Cantor, J. (1997). Confabulation, memory deficits, and frontal dysfunction. Brain and Cognition, 34(2), 189-206.

Johnson, M. K., \& Raye, C. L. (1981). Reality monitoring. Psychological Review, 88(1), 67-85. 
Johnson, M. K., \& Raye, C. L. (1998). False memories and confabulation. Trends in Cognitive Sciences, 2(4), 137-145.

Kapur, N., \& Coughlan, A., K. (1980). Confabulation and frontal lobe dysfunction. Journal of Neurology, Neurosurgery \& Psychiatry, 43(5), 461-463.

Kapur, S. (2003). Psychosis as a state of aberrant salience: A framework linking biology, phenomenology, and pharmacology in schizophrenia. American Journal of Psychiatry, $160(1), 13-23$.

Kay, S. R., Flszbein, A., \& Opfer, L. A. (1987). The positive and negative syndrome scale (PANSS) for schizophrenia. Schizophrenia Bulletin, 13(2), 261-276.

Kern, R. S., Van Gorp, W. G., Cummings, J. L., Brown, W. S., \& Osato, S. S. (1992). Confabulation in Alzheimer's disease. Brain and Cognition, 19(2), 172-182.

Kopelman, M., Guinan, E., \& Lewis, P. (1995). Delusional memory, confabulation, and frontal lobe dysfunction: A case study in de Clérambault's syndrome. Neurocase, 1(1), 71-77.

Kopelman, M. D. (1987). Two types of confabulation. Journal of Neurology, Neurosurgery \& Psychiatry, 50(11), 1482-1487.

Kopelman, M. D. (1999). Varieties of false memory. Cognitive Neuropsychology, 16(3-5), 197214.

Kopelman, M. D., Ng, N., \& Brouke, O. V. D. (1997). Confabulation extending across episodic, personal, and general semantic memory. Cognitive Neuropsychology, 14(5), 683-712. 
Kopelman, M. D. (2010). Varieties of confabulation and delusion. Cognitive Neuropsychiatry, 15(1-3), 14-37.

Korsakoff, S. S. (1891). Erinnerungsteuschungen (pseudoreminiscenzen) bei polyneuritischer psy- chose. Allgemeine Zeitschrift Der Psychiatrie, 47, 390-410.

Korsakoff, S. (1889). Etude médico-psychologique sur une forme des maladies de la mémoire. Revue Philosophique, 28, 501-530.

Kraepelin, E. (1971). Dementia praecox and paraphrenia. New York: Krieger Publishing Company.

Kramer, S., Bryan, K. L., \& Frith, C. D. (1998). 'Confabulation'in narrative discourse by schizophrenic patients. International Journal of Language \& Communication Disorders, 33(S1), 202-207.

La Corte, V., George, N., Pradat-Diehl, P., \& Barba, G. D. (2011). Distorted temporal consciousness and preserved knowing consciousness in confabulation: A case study. Behavioural Neurology, 24(4), 307-315.

Langdon, R., \& Bayne, T. (2010). Delusion and confabulation: Mistakes of perceiving, remembering and believing. Cognitive Neuropsychiatry, 15(1-3), 319-345.

Langdon, R., \& Turner, M. (Eds.). (2010). Delusion and confabulation: A special issue of cognitive neuropsychiatry. Hove: Psychology Press.

Laws, K. R., Evans, J. J., Hodges, J. R., \& McCarthy, R. A. (1995). Naming without knowing 
and appearance without associations: Evidence for constructive processes in semantic memory? Memory, 3(3-4), 409-433.

Lee, E., Kinomura, S., Meguro, K., Akanuma, K., Meguro, M., \& Fukuda, H. (2009). Confabulations on episodic and semantic memory questions are associated with different neurologic backgrounds in Alzheimer's disease. Cognitive and Behavioral Neurology, 22(2), $81-88$.

Lezak, M. D. (2012). Neuropsychological asessment (5th ed.). Oxford: Oxford University Press.

Lezak, M. D. (2004). Neuropsychological assessment. (4th ed.). Oxford: Oxford University Press.

Lindsay, D. (2008). Source monitoring. Cognitive Psychology of Memory, 2, 325-348.

Lorente-Rovira, E., McKenna, P., Berrios, G., Villagrán Moreno, J. M., \& Moro Ipola, M. (2011a). Confabulation (II): Modelos explicativos. Actas Esp.Psiquiatr., 39(6), 384-392.

Lorente-Rovira, E., Pomarol-Clotet, E., McCarthy, R., Berrios, G., \& McKenna, P. (2007). Confabulation in schizophrenia and its relationship to clinical and neuropsychological features of the disorder. Psychological Medicine, 37(10), 1403-1412.

Lorente-Rovira, E., Santos-Gomez, J., Moro, M., Villagrán, J., \& McKenna, P. (2010). Confabulation in schizophrenia: A neuropsychological study. Journal of the International Neuropsychological Society, 16(06), 1018-1026.

Lorente-Rovira, E., McKenna, P., Moro-Ipola, M., \& Villagrán-Moreno, J. M. (2011b). 
Confabulations (I): Concept, classification and neuropathology. Actas EspPsiquiatr, 39(4), 251-259.

Maher, B. A. (1974). Delusional thinking and perceptual disorder. Journal of Individual Psychology, 30(1), 98-113.

Mattioli, F., Miozzo, A., \& Vignolo, L. A. (1999). Confabulation and delusional misidentification: A four year follow-up study. Cortex, 35(3), 413-422.

Mazzoni, G., \& Kirsch, I. (2002). Autobiographical memories and beliefs: A preliminary metacognitive model. In T. J. Perfect, \& B. L. Schwartz (Eds.), Applied metacognition. (pp. 121-145). New York: Cambridge University Press.

McKenna, P. J., Lorente-Rovira, E., \& Berrios, G. E. (2009). Confabulation as a psychiatric symptom. In W. Hirstein (Ed.), Confabulation: Views from Neuroscience, Psychiatry, Psychology and Philosophy (pp. 159-172). New York: Oxford University Press.

McKenna, P. J., \& Oh, T. M. (2005). Schizophrenic speech: Making sense of bathroots and ponds that fall in doorways. New York: Cambridge University Press.

McKenna, P. J. (2007). Schizophrenia and related syndromes (2nd ed.). Hove: Psychology Press.

Menon, M., Schmitz, T. W., Anderson, A. K., Graff, A., Korostil, M., Mamo, D., . . Kapur, S. (2011). Exploring the neural correlates of delusions of reference. Biological Psychiatry, $70(12), 1127-1133$.

Mercer, B., Wapner, W., Gardner, H., \& Benson, D. F. (1977). A study of confabulation. Archives 
of Neurology, 34(7), 429-433.

Metcalf, K., Langdon, R., \& Coltheart, M. (2007). Models of confabulation: A critical review and a new framework. Cognitive Neuropsychology, 24(1), 23-47.

Morais, J., Frith, C., \& Dab, S. (2004). Comprehension, encoding, and monitoring in the production of confabulation in memory: A study with schizophrenic patients. Cognitive Neuropsychiatry, 9(3), 153-182.

Moritz, S., Woodward, T. S., Whitman, J. C., \& Cuttler, C. (2005). Confidence in errors as a possible basis for delusions in schizophrenia. The Journal of Nervous and Mental Disease, 193(1), 9-16.

Morrison, A. P., \& Wells, A. (2003). A comparison of metacognitions in patients with hallucinations, delusions, panic disorder, and non-patient controls. Behaviour Research and Therapy, 41(2), 251-256.

Moscovitch, M. (1989). Confabulation and the frontal systems: Strategic versus associative retrieval in neuropsychological theories of memory. In H. L. Roediger, \& F. I. M. Craik (Eds.), Varieties of memory and consciousness (pp. 133-160). Hillsdale, N.J: Lawrence Erlbaum Associates Inc.

Moscovitch, M. (1995). Confabulation. In D. L. Schacter (Ed.), Memory distortions: How minds, brains, and societies reconstruct the past (pp. 226-251). Cambridge, MA: Harvard University Press.

Moscovitch, M., \& Melo, B. (1997). Strategic retrieval and the frontal lobes: Evidence from 
confabulation and amnesia. Neuropsychologia, 35(7), 1017-1034.

Moscovitch, M., \& Winocur, G. (2002). The frontal cortex and working with memory. In D. T. Stuss, \& R. T. Knight (Eds.), Principles of frontal lobe function. (pp. 188-209). New York: Oxford University Press.

Nahum, L., Ptak, R., Leemann, B., Lalive, P., \& Schnider, A. (2010). Behaviorally spontaneous confabulation in limbic encephalitis: The roles of reality filtering and strategic monitoring. Journal of the International Neuropsychological Society, 16(06), 995-1005.

Nahum, L., Ptak, R., Leemann, B., \& Schnider, A. (2009). Disorientation, confabulation, and extinction capacity: Clues on how the brain creates reality. Biological Psychiatry, 65(11), 966-972.

Nathaniel-James, D., Foong, J., \& Frith, C. (1996). The mechanisms of confabulation in schizophrenia. Neurocase, 2(6), 475-483.

Nathaniel-James, D., \& Frith, C. (1996). Confabulation in schizophrenia: Evidence of a new form? Psychological Medicine, 26(2), 391-400.

Nedjam, Z., Barba, G. D., \& Pillon, B. (2000). Confabulation in a patient with fronto-temporal dementia and a patient with Alzheimer's disease. Cortex, 36(4), 561-577.

Nienow, T. M., \& Docherty, N. M. (2004). Internal source monitoring and thought disorder in schizophrenia. The Journal of Nervous and Mental Disease, 192(10), 696-700.

Nienow, T. M., \& Docherty, N. M. (2005). Internal source monitoring and communication 
disturbance in patients with schizophrenia. Psychological Medicine, 35(12), 1717-1726.

Nuechterlein, K. H., Edell, W. S., Norris, M., \& Dawson, M. E. (1986). Attentional vulnerability indicators, thought disorder, and negative symptoms. Schizophrenia Bulletin, 12(3), 408426.

Overall, J. E., \& Gorham, D. R. (1962). The brief psychiatric rating scale. Psychological Reports, 10(3), 799-812.

Parkin, A. J. (1997). The neuropsychology of false memory. Learning and Individual Differences, 9(4), 341-357.

Salazar-Fraile, J., Tabarés-Seisdedos, R., Selva-Vera, G., Balanzá-Martinez, V., Martínez-Arń, A., Catalán, J., ... Vieta, E. (2004). Recall and recognition confabulation in psychotic and bipolar disorders: Evidence for two different types without unitary mechanisms. Comprehensive Psychiatry, 45(4), 281-288.

Schacter, D. L., Norman, K. A., \& Koutstaal, W. (2000). The cognitive neuroscience of constructive memory. In D. F. Bjorklund (Ed.), False-memory creation in children and adults. (pp. 126-165). New Jersey: Lawrence Erlbaum.

Schnider, A. (2008). The confabulating mind: How the brain creates reality. Oxford: OUP.

Schnider, A., Bonvallat, J., Emond, H., \& Leemann, B. (2005). Reality confusion in spontaneous confabulation. Neurology, 65(7), 1117-1119.

Schnider, A., Guggisberg, A., Nahum, L., Gabriel, D., \& Morand, S. (2010). Dopaminergic 
modulation of rapid reality adaptation in thinking. Neuroscience, 167(3), 583-587.

Schnider, A., \& Ptak, R. (1999). Spontaneous confabulators fail to suppress currently irrelevant memory traces. Nature Neuroscience, 2(7), 677-681.

Schnider, A., Ptak, R., von Däniken, C., \& Remonda, L. (2000). Recovery from spontaneous confabulations parallels recovery of temporal confusion in memory. Neurology, 55(1), 7483.

Schnider, A., von Däniken, C., \& Gutbrod, K. (1996). The mechanisms of spontaneous and provoked confabulations. Brain, 119(4), 1365-1375.

Selva, G., Salazar, J., Balanzá-Martínez, V., Martínez-Arán, A., Rubio, C., Daban, C., . . . Tabarés-Seisdedos, R. (2007). Bipolar I patients with and without a history of psychotic symptoms: Do they differ in their cognitive functioning? Journal of Psychiatric Research, 41(3-4), 265-272.

Semple, D., \& Smyth, R. (2005). Oxford handbook of psychiatry. New York: Oxford University Press.

Shakeel, M. K., \& Docherty, N. M. (2012). Neurocognitive predictors of source monitoring in schizophrenia. Psychiatry Research, 200(2-3), 173-176.

Shakeel, M. K., \& Docherty, N. M. (2014). Confabulations in schizophrenia. Cognitive Neuropsychiatry, (ahead-of-print), 1-13.

Shipley, W. C. (1940). A self-administering scale for measuring intellectual impairment and 
deterioration. The Journal of Psychology, 9(2), 371-377.

Simpson, J., \& Done, D. (2002). Elasticity and confabulation in schizophrenic delusions. Psychological Medicine, 32(3), 451-458.

Spence, S. A., Brooks, D. J., Hirsch, S. R., Liddle, P. F., Meehan, J., \& Grasby, P. M. (1997). A PET study of voluntary movement in schizophrenic patients experiencing passivity phenomena (delusions of alien control). Brain, 120(11), 1997-2011.

Squire, L. R., \& Bayley, P. J. (2007). The neuroscience of remote memory. Current Opinion in Neurobiology, 17(2), 185-196.

Stuss, D. T., Alexander, M. P., Lieberman, A., \& Levine, H. (1978). An extraordinary form of confabulation. Neurology, 28(11), 1166-1166.

Turner, M. S., Cipolotti, L., \& Shallice, T. (2010). Spontaneous confabulation, temporal context confusion and reality monitoring: A study of three patients with anterior communicating artery aneurysms. Journal of the International Neuropsychological Society, 16(6), 984-994.

Turner, M., \& Coltheart, M. (2010). Confabulation and delusion: A common monitoring framework. Cognitive Neuropsychiatry, 15(1-3), 346-376.

Victor, M., \& Yakovlev, P. (1955). SS Korsakoff's psychic disorder in conjunction with peripheral neuritis. Neurology, 5(June), 394-406.

Wechsler, D. (1945). A standardized memory scale for clinical use. The Journal of Psychology, 19(1), 87-95. 
Wernicke, C. (1906). Grundriss der psychiatrie in klinischen vorlesungen. Leipzig: Thieme.

Wilson, R. S., Gilley, D. W., Bennett, D. A., Beckett, L. A., \& Evans, D. A. (2000).

Hallucinations, delusions, and cognitive decline in Alzheimer's disease. Journal of Neurology, Neurosurgery, and Psychiatry, 69(2), 172-177.

Zachary, R. A., \& Shipley, W. C. (1986). Shipley institute of living scale: Revised manual. Los Angeles: Western Psychological Services.

Zaragoza, M. S., Payment, K. E., Ackil, J. K., Drivdahl, S. B., \& Beck, M. (2001). Interviewing witnesses: Forced confabulation and confirmatory feedback increase false memories. Psychological Science, 12(6), 473-477.

Zwanzger, P., Ella, R., Keck, M. E., Rupprecht, R., \& Padberg, F. (2002). Occurrence of delusions during repetitive transcranial magnetic stimulation (rTMS) in major depression. Biological Psychiatry, 51(7), 602-603. 


\section{Tables}

Table 1: Socio-Demographic Details

\begin{tabular}{|c|c|c|c|c|}
\hline & $\begin{array}{l}\text { Schizophrenia } \\
(n=67)\end{array}$ & $\begin{array}{l}\text { Healthy Control } \\
(n=23)\end{array}$ & t-value & Chi-square \\
\hline Mean Age (SD) & $42.97(8.08)$ & $39.95(9.84)$ & -0.72 & \\
\hline Female $(\%)$ & $32(47.8 \%)$ & $12(52.2 \%)$ & & 0.00 \\
\hline Education & $11.60(1.78)$ & $15(2.22)$ & $7.41 * *$ & \\
\hline Parental Education & $11.31(3.14)$ & $12.02(1.88)$ & 1.10 & \\
\hline Unemployment & $54 \%$ & $13 \%$ & & $32.16^{* *}$ \\
\hline Hospitalization (Months) & $9.13(13)$ & - & & \\
\hline GAF & $46.85(13.98)$ & $84.60(8.26)$ & $13.78 * *$ & \\
\hline Race: & & & & 0.40 \\
\hline \multicolumn{5}{|l|}{ African American/African } \\
\hline American \& Caucasian & $42(62.69 \%)$ & $14(61.00 \%)$ & & \\
\hline Caucasian & $24(35.8 \%)$ & $9(39 \%)$ & & \\
\hline Other & $1(1.5 \%)$ & $0(0 \%)$ & & \\
\hline
\end{tabular}




\begin{tabular}{|c|c|c|}
\hline Schizophrenia & $33(49.3 \%)$ & - \\
\hline Schizoaffective, Depressive & $14(20.9 \%)$ & - \\
\hline Schizoaffective, Bipolar & $20(29.9 \%)$ & - \\
\hline \multicolumn{3}{|l|}{ Subtype: } \\
\hline Paranoid & $22(32.8 \%)$ & - \\
\hline Disorganized & $3(4.5 \%)$ & - \\
\hline Undifferentiated & $5(7.5 \%)$ & - \\
\hline \multicolumn{3}{|l|}{ Medication: } \\
\hline Antipsychotics & $60(89.5 \%)$ & - \\
\hline Anti-depressants & $28(41.8 \%)$ & - \\
\hline Mood Stabilizers & $15(22.4 \%)$ & - \\
\hline Anxiolytics & $13(19.4 \%)$ & - \\
\hline Anti-cholinergic & $4(6 \%)$ & - \\
\hline
\end{tabular}


Table 2: True and false memories, Mean (Standard Deviation)

\begin{tabular}{|c|c|c|c|}
\hline & $\begin{array}{l}\text { Schizophrenia } \\
(n=60)\end{array}$ & $\begin{array}{l}\text { Healthy Controls } \\
(n=19)\end{array}$ & t-value \\
\hline Total Memory & $22.10(12.46)$ & $27.95(11.45)$ & 1.84 \\
\hline True Memory & $13.36(8.01)$ & $21.11(9.10)$ & $3.56 * *$ \\
\hline Confabulation Elements & $8.66(8.87)$ & $6.84(3.75)$ & $-0.86^{*}$ \\
\hline Confabulation Elements $\%{ }^{a}$ & $36.80(19.14)$ & $24.17(12.22)$ & $-3.40 * *$ \\
\hline Confabulation Instances & $6.51(9.12)$ & $4.37(3.34)$ & -1.53 \\
\hline Confabulation Instances $\%{ }^{a}$ & $23.96(22.38)$ & $14.85(14.21)$ & $-2.10 *$ \\
\hline Fabricated Elements & $2.31(2.77)$ & $2.26(1.52)$ & -0.07 \\
\hline Fabricated Elements \% & $9.02(7.59)$ & $7.63(5.27)$ & -.74 \\
\hline Non-fabricated Elements & $6.34(7.00)$ & $4.58(2.99)$ & -1.07 \\
\hline Non-fabricated Elements \% & $27.51(17.38)$ & $16.53(11.93)$ & $-3.10 * *$ \\
\hline Repeated Elements ${ }^{\text {a }}$ & $0.84(1.16)$ & $1.58(1.35)$ & $2.35 *$ \\
\hline Repeated Elements Percent ${ }^{\mathrm{a}, \mathrm{b}}$ & $13.20(17.57)$ & $22.36(19.25)$ & 1.94 \\
\hline \multicolumn{4}{|l|}{$* p<.05 ; * * p<.01$} \\
\hline a Schizophrenia $\mathrm{n}=61$ & & & \\
\hline
\end{tabular}


Table 3: Means and standard deviations for elements, cognitive, language related, and psychopathology variables in schizophrenia patients

\begin{tabular}{lc}
\hline & Mean (SD) \\
\hline Elements (log) & $0.84(0.31)$ \\
Temporal Context Confusion & $0.64(0.80)$ \\
True Memory & $13.49(8.29)$ \\
Wisconsin Card Sorting test (Perseverative errors) Standard score & $86.45(13.16)$ \\
Internal Source Monitoring (Discrimination ratio) & $0.65(0.17)$ \\
External Source Monitoring (Discrimination ratio) & $0.73(0.16)$ \\
Shipley Institute of Living Scale-I (vocabulary score) & $22.47(5.33)$ \\
Brief Psychiatry Rating Scale & $48.33(12.94)$ \\
Communication Disturbance Index-Missing Information References & $0.14(0.11)$ \\
Positive and Negative Symptom Scale & $2.16(1.12)$ \\
Verbal Fluency Test & $33.59(8.82)$ \\
Psychotic Symptom Rating Scale Hallucination severity & $4.13(3.36)$ \\
Psychotic Symptom Rating Scale Delusion severity & $13.24(5.32)$ \\
\hline
\end{tabular}


Table 4: Correlations between Temporal Confusions, True Memory, Executive Functions, Source Monitoring, and Confabulation Elements $(\mathrm{n}=56)$

\begin{tabular}{|c|c|c|c|c|c|}
\hline Variables & Elements $(\log )$ & $\mathrm{TCC}$ & True Memory & WCST PE & ISM (DR) \\
\hline $\mathrm{TCC}$ & $.29 *$ & & & & \\
\hline True Memory & .18 & .10 & & & \\
\hline WCST PE & .07 & .08 & -.02 & & \\
\hline ISM (DR) & .14 & .05 & .18 & -.11 & \\
\hline ESM (DR) & .07 & -.01 & .18 & .15 & .23 \\
\hline \multicolumn{6}{|c|}{$* p<.05 ; * * p<.01$} \\
\hline \multicolumn{6}{|c|}{$\mathrm{TCC}=$ Temporal Context Confusion; WCST PE = Wisconsin card sorting task (Perseverative } \\
\hline \multicolumn{6}{|c|}{ errors); ISM $(\mathrm{DR})=$ Internal Source Monitoring (Discrimination Ratio); ESM (DR) = External } \\
\hline
\end{tabular}


Table 5: Regression of True Memory, Executive Functions, and Source Monitoring on Confabulation Elements $(\mathrm{n}=56)$

\begin{tabular}{llll}
\hline & B (SE) & $\beta$ & Partial correlation \\
\hline Constant & $.42(.36)$ & & \\
True Memory & $.01(.00)$ & .16 & .16 \\
WCST PE & $.00(.00)$ & .09 & .09 \\
ISM (DR) & $.24(.27)$ & .13 & .12 \\
ESM (DR) & $-.01(.28)$ & -.01 & -.00 \\
${ }^{*} p<.05 ; * * p .01$ & \\
$R=.23 ; R^{2}=.05 ;$ Adjusted $R^{2}=-.02 ; F(4,51)=0.72(p>.05)$ \\
WCST PE = Wisconsin Card Sorting Task (Perseverative Errors); ISM (DR) = Internal Source \\
Monitoring (Discrimination Ratio); ESM (DR) = External Source Monitoring (Discrimination \\
Ratio).
\end{tabular}


Table 6: Correlations of Language, Formal Thought Disorder, and Verbal Fluency with Confabulation Elements $(n=49)$

\begin{tabular}{lllllll}
\hline Variables & Elements $(\log )$ & Shipley & True Memory & BPRS & CDI-MIR & PANSS \\
\hline Shipley & .03 & & & & \\
True & .17 & -.04 & & & \\
Memory & & & & & & \\
BPRS & .04 & -.18 & -.02 & & & \\
CDI-MIR & $.24 *$ & $-.28 *$ & -.07 & .12 & & \\
PANSS-CD & $.27 *$ & -.10 & -.20 & $.27 *$ & $.37 * *$ & $-.27 *$ \\
VFT & -.01 & $.29 *$ & $.31 *$ & .04 & -.10 & \\
\hline$* p<.05 ; * p<.01$ & & & & & &
\end{tabular}

Shipley = Shipley Institute of Living Scale-I (vocabulary score); BPRS = Brief Psychiatry Rating Scale (minus conceptual disorganization score); CDI-MIR = Communication Disturbance IndexMissing Information References; PANSS = Positive and Negative Symptom Scale (Conceptual Disorganization): VFT = Verbal Fluency Test. 
Table 7: Regression of Language, Formal Thought Disorder, and Verbal Fluency Variables on Confabulation Elements $(\mathrm{n}=49)$

\begin{tabular}{llll}
\hline & B (SE) & $\beta$ & Partial correlation \\
\hline Step 1 & & & \\
Constant & $.62(.33)$ & & \\
Shipley & $.00(.01)$ & .05 & .05 \\
True Memory & $.01(.01)$ & .17 & .17 \\
BPRS & $.00(.00)$ & .06 & .05 \\
Step 2 & & & \\
Constant & $.35(.35)$ & & \\
CDI-MIR & $.60(.47)$ & .20 & .20 \\
PANSS-CD & $.08(.05)$ & .25 & .23 \\
VFT & $-.00(.01)$ & -.04 & -.04 \\
\hline * $p<.05 ; * *<<.01$ & &
\end{tabular}

Final Model $R=.18 ; R^{2}=.03 ;$ Adjusted $R^{2}=-.03 ; F(6,42)=1.37(p>.05)$

Shipley $=$ Shipley Institute of Living Scale-I (vocabulary score); BPRS = Brief Psychiatry Rating Scale (minus conceptual disorganization score); CDI-MIR = Communication Disturbance IndexMissing Information References; PANSS-CD = Positive and Negative Symptom Scale (Conceptual Disorganization): VFT = Verbal Fluency Test. 
Table 8: Correlation of Confabulation Elements with Hallucinations and Delusions $(n=46)$

\begin{tabular}{llll}
\hline Variables & Elements $(\log )$ & BPRS & PSYRATS Hallucination \\
\hline BPRS & .01 & & \\
PSYRATS Hallucination & .21 & .23 & \\
PSYRATS Delusion & $-.26^{*}$ & .24 & $.50^{* *}$ \\
\hline${ }^{*} p<.05 ; * *<<.01$ & & \\
PSYRATS = Psychotic Symptom Rating Scales \\
BPRS = Brief Psychiatry Rating Scale (minus hallucination and delusion score)
\end{tabular}


Table 9: Regression of Positive Symptoms on Confabulation Elements $(n=46)$

$\mathrm{B}(\mathrm{SE}) \quad \beta \quad$ Partial correlation

\section{Step 1}

Constant

$0.86(.24)$

$\begin{array}{llll}\text { BPRS } & 0.00(.01) & .01 & .01\end{array}$

Step 2

Constant

$1.07(.23)$

PSYRATS Hallucination

$0.04(.02)^{* *} \quad .44^{* *} \quad .40$

PSYRATS Delusion

$-0.03(.01)^{* *} \quad-.49^{* *} \quad-.43$

${ }^{*} p<.05 ; * * p<.01$

Final model $R=.47 ; R^{2}=.22 ;$ Adjusted $R^{2}=.16 ; F(3,39)=3.70(p<.05)$

PSYRATS $=$ Psychotic Symptom Rating Scales

BPRS $=$ Brief Psychiatry rating Scale (minus hallucination and delusion score) 


\section{Figures}

Figure 1: False Memories in Schizophrenia Patients and Healthy Controls (Expressed in Percentage of Total Memory)

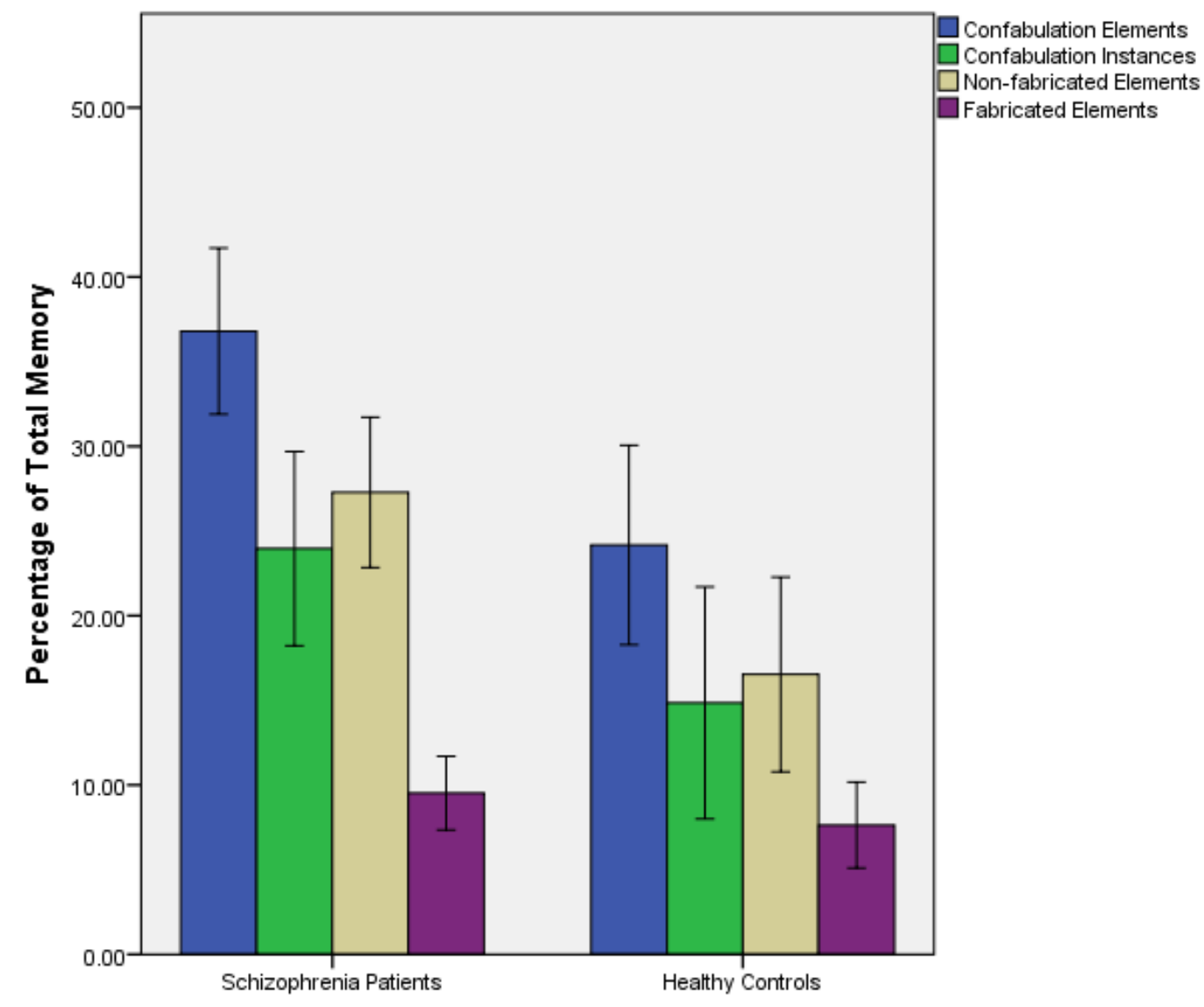




\section{APPENDIX A. Confabulation Coding Scheme}

\section{Definition:}

Confabulation is new information which adds irrelevant or inaccurate material, or changes the sense of a memory (Kopelman, 1987).

\section{What are confabulations?}

When a participant mentions a new physical/verbal action which did not occur in the original video, it is codes as a confabulation (thoughts, opinions, inferences, etc. are not coded as confabulations). Examples:

- Physical action: A physical action that did not occur in the movie ("His brother drowned").

- Verbal action: Any verbal action the characters did not say ("The lady said she wanted to show her friends the camp").

Note: The present coding scheme is implemented on transcripts of week 8 free and cued recall session. Week 1 transcripts are only coded for fabricated confabulations (described later)

What are not confabulations?

Confabulation does not include:

- Confusing names (e.g., calling Delaney Sullivan), except when identities are confused ("Sullivan (the younger brother) killed the snake").

- Plausible inferences which does not change the meaning of the story. E.g, "I think they had eaten everything. I didn't see 'em, but I think they had just came (sic) out of...the chow hall eating,"

- Elaborative inferences, where the participant is inferring from a fact "(He sees his brother in the water)...and I think his brother couldn't swim."

- Sentences that reflect obvious thought disorder (FTD) are not confabulations. E.g., "Mike Tyson bit off someone's ear."

- Ambiguous statements, or general factual information ('the lady was running the camp').

- True events recalled as part of a different scene. These are coded as a temporal context confusion (TCC).

The statement has to be a commission error involving a new verbal or physical action to be a confabulation.

\section{Elements}

An element is the basic unit of confabulation. Each individual act of confabulation (physical/verbal) constitutes an element. Examples:

- "Ratface put the banana peel on the floor."

- "The Chief went on vacation". 
If a sentence has more than one actions, it is codes as multiple elements. Example

- Ratface got caught for putting the banana peel on the floor. (2 elements).

Notes on coding Elements:

- Elements should be stated verbatim in the Rating Form ["Delaney then...threw it (the snake) into the water"].

- The coded ratings should stand alone (readers should not have to constantly refer to the original transcript to understand it.) So the surrounding phrase/s should be included to give the reader the context of the confabulation. For example, instead of "Delaney put it back in the water", note "Delaney (got the snake with the oar and) put it back in the water".

- Confabulations also include statements the participant is unsure of ("I think/guess/assume/but I'm not sure/I don't know if that really happened"). Example:

- "Maybe they went to the girl's camp and got drunk."

- "I think the Chief placed the snake on the boat."

- "I guess she knocked him over (into the lake)....then she had to rescue (Delaney) from the water" (this example contains more than one element).

- "They might have been drinking or something...but they ended up falling asleep or something...and didn't get back in time..." (This example contains more than one element).

- If the participant corrects herself, it is not coded as a confabulation. E.g., one participant initially says the snake was in the cabin and later says it was actually in the cage.

If there are several guessed responses for the same action, they are coded as one element ([e.g., 'Sullivan was by the water maybe fishing, or smoking, or eating something...')

\section{Instances}

An instance contains 2 or more elements which are causally or temporally related. Often, it is like a subplot within the story. The entire transcript is considered when coding instances, because patients often elaborate on the instance in different parts of the interview. Example:

3. Instance 1: (Ratface throws paint on the Chief)*

1. 1. "Ratface put banana peel on the dining floor (to make the Chief fall)".

2. 2. "Ratface does something and gets caught"

3. 3. "Chief (thinks Delaney was responsible and) gets ready to get rid of Delaney".

4. 4. "...but finds out the truth through Delaney and Sullivan"

5. 5. "Chief apologizes to Delaney"

4. Instance 2: Instructor in Hospital

1. 1. "Instructor was probably telling the old ladies about the snakes"

2. 2. "(He gets bitten) and they rushed him into a hospital and got the venom out"

3. 3. "Everybody laughs at him...because he...got bit"

4. 4. "They laugh at him because he had said earlier that these snakes are biting everything, and now he got bitten"

[*Instances are given titles where possible (for convenience)]

Notes on coding instances:

The elements have to be causally or temporally related. When elements are not logically related, they are treated as separate instances. 
1. Example: Instance with causal relation (each of these statements occur in different parts of free and cued recall).

Instance (Chief gets paint):

1. "Chief was trying to date a girl"

2. "Ratface and his crew saw this"

3. "They poured paint on the Chief"

2. Example: Instance with temporal relation (each of these statements occur close to each other). Instance (Sullivan dies):

1. "Sullivan snuck out at night with Delaney"

2. "Sullivan fell into the water"

3. "Sullivan fell sick"

4. "Sullivan died"

For data analysis, the number of elements within instances are added to give a total instance score (E.g., the above example has a total instance score of 4).

Non-fabricated confabulations

Number of elements and instances of confabulations for scenes which did not have any segment missing (i.e., for all scenes other than the 'Sneak' and 'Prank' scene)

Fabricated confabulations

Confabulations for Sneak/Prank events are noted separately, because they originate in response to the investigator's prompts at week 1 and hence are distinct from confabulations which occur spontaneously (without misleading questions). They are coded for elements and instances as stated above.

Note: Fabricated confabulation elements are coded for week 8 as well as week 1 interview. Repeated Confabulations

Repeated confabulations are elements which were present in forced fabrication (Sneak/Prank) scenes of week 1 interview and are again repeated at week 8 .

\section{True Memory Checklist}

If the participant mentions any of the items in the memory checklist, place a " $T$ " next to it. Also, make a subjective evaluation of how much the participant remembers of each scene, taking into consideration details present in the movie but not mentioned in the checklist (e.g., "There were more than a dozen children standing outside"; "Lady talks about how her late husband founded the camp"). The memory checklist is also used to code for temporal context confusions (see below). Each scene is coded on the following scale

- Code 0: Remembers nothing

- Code 1: Remembers up to $25 \%$ of the information in the scene

- Code 2: Remembers $26-50 \%$ of the information in the scene

- Code 3: Remembers $51-75 \%$ of the information in the scene

- Code 4: Remembers 76-100\% of the information in the scene

True memory percentage is calculated as:

True memory $\%=[($ Memory recall code total / 36) $) \times 100]$, where 36 is the total possible score on the memory code.

To convert true memory percentage into number of true memories, use:

True memory score $=[($ True Memory \% / 100) x 63], where 63 is the total number of items on the memory checklist. 
Arriving at true memory score this way results in scores very similar to simply adding the numbers on the checklist, but has the added benefit of giving participants credit for information they might have recalled but was not mentioned on the checklist.

\section{Temporal Context Confusion (TCC)}

TCCs are true events recalled in the wrong context. When one event is followed by another event which occurs before it in the movie, then the second event is coded as a TCC.

- TCC should be underlined on the transcript and noted next to the checklist item.

- TCC has to be a true event, therefore no event can be both TCC and confabulation.

Notes on coding TCC:

- If the video contains events A-J, following each other (A-B-C-D-E-F-G....-J), TCC is coded as below:

- EVENT A- True event (T)

- EVENT B-True event (T)

- EVENT C-True event (T)

- EVENT F-True event (T)

- EVENT D-Temporal Context Confusion (TCC)

- EVENT E-True event (T)

- Another example:

- EVENT A-True event (T)

- EVENT D-True event (T)

- EVENT B-Temporal Context Confusion (TCC)

- EVENT C-True event (T)

- EVENT E-True event (T)

- EVENT F-True event (T)

- EVENT I-True event (T)

- EVENT G- Temporal Context Confusion (TCC)

- EVENT J-True event (T)

- TCC is coded only when scenes are displaced in order. So if someone merely skips scenes forwards (due to poor memory), there is no TCC. e.g.,

- EVENT A-True event (T)

- EVENT C-True event (T)

- EVENT G-True event (T)

- EVENT H-True event (T)

- EVENT I-True event (T)

- Explaining a previous event A after mentioning a later one B is not TCC. TCC occurs only if the participant remembers event B as having occurred after event A. As with Delaney in this example (p2102):

- Delaney was crying (T)

- (and) Sullivan was crying because he didn't have friends (TCC) 
- Delaney was crying because he lost his scholarship (not TCC)

True Memory Coding

\section{Memory Rating Form}

Code 0: Remembers nothing

Code 1: Remembers up to $25 \%$ of the information in the scene

Code 2: Remembers $26-50 \%$ of the information in the scene

Code 3: Remembers $51-75 \%$ of the information in the scene

Code 4: Remembers $76-100 \%$ of the information in the scene

True memory $\%=[($ Memory recall code total $/ 36) \times 100]$

True memory score $=[($ True Memory \% / 100) x 63]

\section{True Memory Checklist}

Announcement

1. Man introduces Lady

2. Lady gives speech

3. Ratface fights with a boy

4. Ratface talks back to the lady

5. Counselor scolds Ratface

Memory code:

$\underline{\text { Snake bite }}$

6. Counselor talks about snakes

7. Snake bites counselor

8. Chief goes to get serum (from girl's camp)

9. Counselor's leg is cut open with a pocketknife

10. A nurse arrives

11. A counselor is asked to suck out the blood

12. The wounded counselor is propped up

13. Delaney faints at the sight of blood

14. Counselors make fun of Delaney after he wakes up

15. Sullivan stands up for Delaney

16. Delaney scolds Sullivan.

17. Ladies arrive at the camp in cars

Memory code:

Dining Hall

18. Everyone is sitting in the dining hall

19. Man (chef) brings a cake

20. Everyone cheers for Moose

21. Delaney gets up to make an announcement

22. Delaney falls

23. Everyone laughs at Delaney

24. Man (chef) makes fun of Delaney

25. Lady scolds Delaney

Memory code: 
$\underline{\text { Ladies on canoes }}$

26. Ladies walk to the canoes

27. Ladies talk about snakes

28. Ladies and counselors get into the boats/canoes

29. They tour the lake in the canoes

30. Delaney talks about history

31 . There is a snake on the boat

32. Ladies see a snake

33. They jump into the lake

34. Delaney sees the snake

35. Delaney kills snake (with oar)

36. Ladies get on to the other boats

37. Chief lifts dead snake (with oar)

38. Chief praises Delaney

39. Everyone cheers

40. Delaney suggests starting wrestling program

Memory code:

Sullivan in water

41. Ratface (and another boy) push Sullivan into the water (and try to dunk him)

42. Delaney (chases them away and) helps Sullivan out

43. Delaney asks Sullivan to make (new) friends

44. Sullivan says he has no friends

45. Sullivan says he does not want his brother sticking up for him

46. Sullivan cries and runs away

47. Moe teaches wrestling to the children

48. Delaney asks Moe to pay attention to Sullivan

49. Moe says Sullivan is good at wrestling

Memory code:

Nurse's Laundry

50. A counselor watches nurse drying clothes (using binoculars)

51. He tells others she is trying to send him a secret message

52. Another counselor blows a trumpet

53. Two counselors go to see the nurse

Memory code:

Sneak

54. Moe and Delaney sneak out in a boat.

Memory code:

Chief Yelling

55. Chief calls Delaney to his office

56. Chief scolds Delaney

57. Chief says Delaney has tarnished the reputation of the camp

58. Moe tells Delaney he has case of poison ivy (/fell ill)

59. Delaney says he did not tell the chief anything (about Moe)

Memory code:

Delaney upset

60. Sullivan tells Delaney he wants to shows him his swimming 
61. Delaney is upset

62. Sullivan asks why Delaney is upset

63. Delaney (tells Sullivan he) lost the scholarship

Memory code: Total no. of TCC $=$

True Memory $\%=$

True Memory score $=$

\section{Confabulations Rating Form}

Non-fabricated confabulation [Bright red]: Highlight on transcripts in Red

Fabricated confabulation [Light Blue]: Highlight on transcripts in Blue

\section{Non-fabricated confabulations:}

Instance 1:

- Element 1:

- Element 2:

- Element 3:

- Element 4:

- Element 5:

Instance 2:

- Element 1:

- Element 2:

- Element 3:

- Element 4:

- Element 5:

Elements (unrelated to each other):

- Element 1:

- Element 2:

- Element 3:

- Element 4:

- Element 5:

Fabricated confabulations:

Instance 1:

- Element 1:

- Element 2:

- Element 3:

- Element 4:

- Element 5:

Instance 2:

- Element 1:

- Element 2:

- Element 3:

- Element 4:

- Element 5: 
Elements (unrelated to each other):

- Element 1:

- Element 2:

- Element 3:

- Element 4:

Element 5: Repeated confabulations: No. of elements in this section (fabricated confabulations) present at the week 1 interview:

- Element 1:

- Element 2:

- Element 3:

- Element 4:

- Element 5:

Total no. of instances of non-fabricated confabulation $=$ Total no. of elements of non-fabricated confabulation $=$ Total no. of instances of fabricated confabulation $=$ Total no. of elements of fabricated confabulation $=$ Total no. of repeated confabulations $=$ 